\title{
Tradução de uma Obra de Gauss
}

\author{
Translation of a Work by Gauss \\ A. K. T. Assis \\ Instituto de Física 'Gleb Wataghin' \\ Universidade Estadual de Campinas - Unicamp \\ 13083-970 Campinas, SP \\ Homepage: http://www.ifi.unicamp.br/ assis \\ Email: assis@ifi.unicamp.br
}

Recebido em 3 de fevereiro, 2003. Aceito em 28 de fevereiro, 2003.

\begin{abstract}
Apresentamos a primeira tradução para o português do trabalho fundamental de Gauss que é a base do sistema absoluto de medidas eletromagnéticas.
\end{abstract}

We present the first portuguese translation of the fundamental work by Gauss which is the basis of the absolute system of electromagnetic measures.

\section{Introdução}

Apresentamos aqui a primeira tradução para o português do trabalho fundamental de Carl Friedrich Gauss (1777-1855) que é a base de todo o sistema absoluto de medidas eletromagnéticas. Este tratado, Intensitas vis magneticae terrestris ad mensuram absolutam revocata, foi lido por Gauss na Academia de Ciências de Göttingen em 15 de dezembro de 1832 e publicada no Volume 8 dos tratados desta Sociedade (Göttingen Gelehrte Anzeigen, 1841), págs. 3-44. Está reproduzida nas Obras Completas de Gauss, Vol. 5, pp. 79118.

Há uma tradução para o alemão em Annalen der Physik und Chemie, Vol. 28 (=104), número 6, pp. 241-273 e número 8 , pp. 591-615 (1833), assim como uma outra comentada feita pelo Dr. Kiel em Bonn e publicada em: Ostwald's Klassiker der Exakten Wissenschaften, número 53 (Wilhelm Engelmann, Leipzig, 1894), editada por E. Dorn. Há também traduções do trabalho completo para o francês (1834), italiano (1838) e russo (1952), ver U. C. Merzbach, Carl Friedrich Gauss: A Bibliography (Scholarly Resources Inc., Wilmington, Delaware, 1984), p. 35. Há também uma tradução para o inglês, ainda não publicada, realizada por S. P. Johnson, ver: L. Hecht, Experimental apparatus and instrumentation, $21^{\text {st }}$ Century Science \& Technology, Vol. 9 (3), pp. 35-37 (1996), especialmente Nota 1. Utilizamos para realizar esta tradução as duas versões em alemão e a ainda não publicada em inglês. Para dar o contexto e o significado deste trabalho de Gauss incluímos também a tradução em português dos comentários importantes feitos por E. Dorn relacionados ao trabalho de Gauss de 1832, comentários estes que se encontram na série de clássicos da ciência de Ostwald mencionada acima. Não te- mos conhecimento de nenhuma tradução para o inglês nem para qualquer outro idioma destes comentários de Dorn, de tal forma que os traduzimos partindo apenas do original em alemão. Esta tradução encontra-se ao final deste artigo.

De acordo com Merzbacher (ver referência acima, p. 323), pelo menos até 1984 nunca foram publicadas traduções de nenhum trabalho de Gauss para o português nem para o espanhol. Não temos conhecimento de nenhuma modificação em relação a isto desde então. Com esta tradução espera-se contribuir para superar esta deficiência.

Os termos entre colchetes, [], são de nossa autoria.

Agradecimentos: $O$ tradutor agradece à Fundação Humboldt da Alemanha pela concessão de uma bolsa de pesquisa Humboldt desenvolvida na cidade de Hamburgo, Alemanha, durante a qual foi realizado este trabalho. Agradece ainda ao Dr. L. Hecht por ter lhe enviado a tradução inglesa deste trabalho de Gauss ainda não publicada.

\section{A Intensidade da Força Magnética Terrestre Reduzida a Medida Absoluta}

\section{Carl Friedrich Gauss}

Para a determinação completa da força magnética terrestre numa certa localização são necessários três elementos: o desvio (declinação) ou o ângulo entre o plano no qual ela age e o plano meridiano; a inclinação da direção [desta força] em relação ao plano horizontal; e finalmente o terceiro, a magnitude (intensidade). A declinação, que é para ser considerada como o elemento mais importante em todas as aplicações da navegação e da geodesia, tem atraído a atenção de astrônomos e físicos desde o início, os quais já por um século têm dado sua atenção constante também para a inclinação. O terceiro elemento, a intensidade da força 
magnética terrestre, ao contrário, o qual certamente é um assunto de igual valor para a ciência, permaneceu totalmente desprezado até épocas mais recentes. A Humboldt deve-se o mérito, entre tantos outros, de ter sido o primeiro a direcionar sua atenção para este assunto, sendo que em suas viagens juntou uma grande quantidade de observações relativas à magnitude relativa do magnetismo, que forneceu o resultado de um aumento contínuo desta magnitude desde o equador magnético em direção ao pólo. Muitos físicos seguiram as pegadas deste grande cientista e já juntaram uma quantidade tão grande de determinações que Hansteen, muito respeitado por seu conhecimento do magnetismo terrestre, publicou recentemente um compreensivo mapa isodinâmico.

O método empregado em todas estas pesquisas consiste em observar ou o intervalo de tempo que leva para uma mesma agulha magnetizada realizar o mesmo número de oscilações em locais diferentes, ou o número de oscilações da mesma agulha no mesmo intervalo de tempo [em locais diferentes], e se assume ser a magnitude proporcional ao quadrado do número de oscilações num certo intervalo de tempo. Desta maneira todas as intensidades são comparadas uma com a outra, quando uma agulha de inclinação, suspensa pelo centro de gravidade, oscila num eixo horizontal perpendicular ao meridiano magnético, ou a componente horizontal, quando uma agulha horizontal oscila ao redor de um eixo vertical. O último modo de observação leva a uma precisão maior, e os resultados que surgem daqui podem, após determinar-se a inclinação, ser facilmente relacionados às intensidades totais.

É evidente que a confiabilidade deste procedimento depende da suposição que a distribuição do magnetismo livre nas partículas da agulha usada nesta comparação permanece invariável durante as experiências individuais; isto é, se a força magnética da agulha tivesse sofrido qualquer tipo de enfraquecimento ao longo do tempo, ela oscilaria subsequentemente mais lentamente, e o observador, que não tem conhecimento de tal alteração, atribuiria um valor muito baixo à magnitude do magnetismo terrestre para a localização subsequente. Se as experiências ocorrem apenas num intervalo de tempo moderado e se a agulha é feita de aço bem temperado e magnetizada cuidadosamente, não é para ser esperado um enfraquecimento significativo da força; além disto, a incerteza será ainda mais diminuída, se várias agulhas são utilizadas como comparação; finalmente, esta suposição será mais confiável se for verificado, após retornar ao local inicial, que a duração da oscilação da agulha não modificou-se. Contudo quaisquer que sejam as precauções, dificilmente pode ser evitado um enfraquecimento lento da força da agulha, e portanto dificilmente será esperada tal concordância após uma longa ausência. Portanto, ao comparar intensidades para locais muito distantes sobre a terra, não pode ser obtida uma precisão com o grau que desejamos.

De resto, esta desvantagem no método é menos importante desde que seja apenas uma questão de comparar intensidades simultâneas ou intensidades correspondentes a intervalos de tempo não distantes um do outro. Mas como a experiência nos ensinou que tanto a declinação quanto a inclinação sofrem mudanças contínuas num certo local, que tornam-se muito grandes após muitos anos, não pode ser duvidado que a intensidade do magnetismo terrestre está sujeita a mudanças seculares análogas. É evidente, tão logo surge esta questão, que o método descrito acima perde toda utilidade. E contudo seria altamente desejável para o progresso da ciência que esta questão altamente importante fosse completamente resolvida, o que não pode ocorrer se um outro método não substitui este puramente relativo, e se a intensidade do magnetismo terrestre não for reduzida a unidades fixas e a medida independente.

Não é difícil especificar os princípios teóricos fundamentais nos quais tem de ser baseado este método a tanto tempo desejado. O número de oscilações efetuado por uma agulha num certo intervalo de tempo depende da intensidade do magnetismo terrestre assim como do estado da agulha, a saber, do momento [magnético] estático dos elementos contidos nela e do seu momento de inércia. Como este momento de inércia pode ser obtido sem maiores dificuldades, fica evidente que a observação das oscilações nos forneceria o produto da intensidade do magnetismo terrestre com o momento estático do magnetismo da agulha. Mas estas duas grandezas não podem ser separadas, se não são feitas adicionalmente observações de um outro tipo que fornecem uma relação diferente entre elas. Este objetivo pode ser alcançado se uma segunda agulha é adicionada como auxiliar e exposta à influência do magnetismo terrestre e da primeira agulha, com o objetivo de determinar a relação destas duas forças entre si. Cada um destes dois efeitos dependerá obviamente da distribuição do magnetismo livre na segunda agulha, mas o segundo vai depender além disto do estado da primeira agulha, da distância entre seus pontos médios, da posição da linha reta conectando seus pontos médios, e finalmente das leis de atração e repulsão magnética. Tobias Mayer foi o primeiro a sugerir que esta lei está em concordância com a lei da gravitação, já que este efeito também cai com o quadrado da distância; as experiências de Coulomb e Hansteen forneceram grande plausibilidade a esta sugestão, e as últimas experiências a elevaram acima de qualquer suspeita. Mas é bom notar que esta lei se refere apenas aos elementos individuais do magnetismo livre; o efeito total de um corpo magnético será completamente diferente e, a distâncias muito grandes, será aproximadamente proporcional ao inverso do cubo da distância, como pode ser deduzido por esta própria lei, de tal forma que, outras condições sendo iguais, a ação da agulha multiplicada pelo cubo da distância, dadas distâncias cada vez maiores, aproxima-se de um valor limite. Este valor limite, tão logo um comprimento definido seja tomado como unidade, e as distâncias sejam expressas numericamente, será do mesmo tipo que o efeito da força [magnética] terrestre, e comparável com ela.

Através de experiências preparadas e realizadas apropriadamente pode-se determinar o valor limite desta relação. Como o limite contem apenas o momento estático do magnetismo da primeira agulha, então a razão deste momento dividido pela intensidade do magnetismo terrestre será obtida, se ela é agora comparada com o produto já obtido destas grandezas, servirá para eliminar este momento estático e fornecerá o valor da intensidade do magnetismo terrestre.

Com relação às possíveis maneiras de testar os efeitos 
do magnetismo terrestre e da primeira agulha sobre a segunda agulha, há duas possibilidades, pois a segunda agulha pode ser observada ou em estado de movimento ou em estado de equilíbrio. O primeiro método consiste em observar as oscilações desta segunda agulha enquanto o efeito do magnetismo terrestre é associado com a ação da primeira agulha. Esta primeira agulha tem de ser colocada a uma distância conveniente tal que seu eixo esteja sobre o meridiano magnético passando através do ponto médio da agulha oscilante. Por este meio as oscilações são ou aceleradas ou retardadas, dependendo se os pólos opostos ou iguais estão apontando em direção um ao outro, e a comparação entre si ou dos tempos de oscilação para cada uma das duas posições da primeira agulha, ou do tempo de oscilação de uma das duas posições com o tempo de oscilação que (após distanciar a primeira agulha) acontece sob o efeito apenas do magnetismo terrestre, nos mostrará a relação desta força para o efeito da primeira agulha. No segundo método, a primeira agulha é colocada de tal forma que a direção de sua força exercida na localização da segunda agulha suspensa livremente, forma um ângulo (por exemplo, um ângulo reto) com o meridiano magnético; desta forma a segunda agulha será desviada para fora do meridiano magnético, e a partir da grandeza deste desvio, pode-se inferir a relação entre a força magnética terrestre e a influência da primeira agulha.

A propósito, o primeiro método coincide essencialmente com aquele proposto há alguns anos por Poisson. Mas as experiências efetuadas por certos físicos de acordo com esta formulação, pelo menos até onde sei, falharam totalmente, ou podem no máximo ser consideradas como aproximações imperfeitas.

A dificuldade real reside no fato de que a partir das influências observadas da agulha a distâncias moderadas, pode-se calcular um limite que baseia-se, essencialmente, numa distância infinitamente grande, e que as eliminações necessárias para este fim são perturbadas pelos menores erros nas observações, na verdade são tornadas totalmente inúteis, quanto mais estas [quantidades] desconhecidas, que dependem da condição específica da agulha, têm de ser eliminadas. O cálculo pode apenas ser reduzido a um número pequeno de incógnitas, contudo, quando as influências ocorrem a distâncias que tornam-se bem grandes em relação ao comprimento da agulha, elas tornam-se muito pequenas. Mas para medir influências tão pequenas os procedimentos práticos empregados até agora são insuficientes.

Reconheci que tinha de devotar meus esforços acima de tudo em descobrir novos expedientes através dos quais os alinhamentos da agulha pudessem ser observados e medidos com uma precisão muito maior do que antes. Os esforços levados a cabo para este fim, que foram realizados durante vários meses, e nos quais fui auxiliado por Weber de muitas formas, levaram ao objetivo desejado, ao ponto de que eles não apenas não desapontaram as expectativas, mas as excederam de muito. E nada mais resta a ser desejado com o objetivo de tornar a precisão das experiências equivalente à acuidade das observações astronômicas, a não ser um local totalmente protegido da influência do ferro em suas proximidades e das correntes de ar. Dois equipamentos foram colocados à nossa disposição que são repu- tados tanto pela simplicidade quanto pela precisão que permitem. Deixo a descrição destes equipamentos para uma outra época, enquanto submeto aos físicos no tratado seguinte as experiências efetuadas até o momento em nosso observatório com o objetivo de determinar a intensidade do magnetismo terrestre.

\section{1.}

Para explicar os fenômenos magnéticos assumimos dois fluidos magnéticos: a um chamamos de norte e ao outro de sul. Supomos que os elementos de um fluido atraem aqueles do outro fluido e que por outro lado dois elementos do mesmo fluido repelem-se mutuamente, e que cada um destes efeitos altera-se na razão inversa do quadrado da distância. Será mostrado abaixo que a própria exatidão desta lei foi confirmada por nossas observações.

Estes fluidos não ocorrem independentemente, mas apenas em associação com as partículas ponderáveis dos corpos que admitem o magnetismo, e seus efeitos manifestam-se ou quando eles colocam os corpos em movimento ou quando evitam ou transformam o movimento que seria gerado por outras forças, por exemplo pela força da gravidade, agindo sobre estes corpos.

Portanto o efeito de uma dada quantidade de fluido magnético sobre uma dada quantidade seja do mesmo fluido ou do fluido oposto a uma dada distância é comparável ao efeito de uma força motriz dada, isto é, com o efeito de uma força aceleradora sobre uma dada massa, e como os próprios fluidos magnéticos só podem ser conhecidos através dos efeitos que eles próprios geram, estes últimos [efeitos] têm de servir para medir os primeiros [fluidos magnéticos].

Contudo, para que sejamos capazes de reduzir esta medida a conceitos definidos, acima de tudo têm de ser estabelecidas unidades para três tipos de grandezas, a saber, a unidade de distância, a unidade de massa ponderável, e a unidade de aceleração. Para a terceira, pode ser assumida a gravidade no local da observação. Se, contudo, isto não for conveniente, a unidade de tempo também tem de entrar, e para nós será = 1 a aceleração que, na unidade de tempo, produz uma mudança de velocidade do corpo na direção de seu movimento que é equivalente à unidade.

Correspondentemente, a unidade da quantidade de fluido norte será aquela cujo efeito repulsivo numa outra quantidade igual a ela separada pela unidade de distância é $=1$ [unidade] da quantidade de força motriz, isto é, o efeito de uma força aceleradora $=1$ sobre uma massa $=1$; o mesmo será verdadeiro para uma unidade da quantidade de fluido sul. Nesta definição claramente o fluido ativo, assim como aquele do efeito, têm de ser pensados como, fundamentalmente, concentrados em pontos físicos. Além disto, contudo, tem de ser assumido que a atração entre quantidades dadas de tipos diferentes de fluidos a uma dada distância é igual à repulsão entre as mesmas quantidades do mesmo tipo de fluido. Portanto o efeito de uma quantidade $m$ do fluido magnético norte sobre uma quantidade $m^{\prime}$ do mesmo fluido a uma distância $r$ (cada um dos dois fluidos sendo assumidos como concentrados em pontos) será expresso como $\frac{m m^{\prime}}{r r}$, ou é equivalente a uma força motriz $=\frac{m m^{\prime}}{r r}$, que age 
na direção do primeiro em direção ao segundo fluido, e evidentemente esta fórmula vale em geral quando, como daqui para a frente queremos estipular, uma quantidade do fluido sul será considerada como negativa, e um valor negativo da força significará atração.

Portanto se quantidades iguais de fluido norte e sul são encontradas simultaneamente num ponto físico, nenhum efeito surgirá. Contudo, se as quantidades são desiguais, apenas o excesso de uma que queremos chamar de magnetismo livre (positivo ou negativo) será levado em consideração.

A estas precondições fundamentais temos de adicionar uma outra, que é sempre confirmada pela experiência, a saber, que todo corpo no qual estão presentes fluidos magnéticos sempre contem uma quantidade igual de cada um dos dois [fluidos]. A experiência mostra até mesmo que esta suposição é para ser estendida às menores partículas deste corpo que ainda podem ser diferenciadas por nossos sentidos. Contudo, de acordo com o que enfatizamos no final da seção precedente, um efeito só pode surgir desde que ocorra uma separação dos fluidos, de tal forma que temos de necessariamente assumir que isto ocorre através de intervalos tão pequenos que são inacessíveis a nossas medidas.

Um corpo magnetizado tem de ser concebido então como a união de inúmeras partículas, das quais cada uma contem uma certa quantidade do fluido magnético norte e uma quantidade igualmente grande do sul, especificamente, de tal forma que eles estão ou homogeneamente misturados (o magnetismo é latente), ou sofreram uma maior ou menor separação (o magnetismo está desenvolvido), uma separação, contudo, que nunca pode envolver uma transferência de fluido de uma partícula para a outra. Não faz diferença se assumimos que uma maior separação originase de uma maior quantidade de fluido liberado ou de um maior espaçamento entre eles. Mas é evidente que além do tamanho da separação sua direcionalidade tenha de ser levada em conta simultaneamente, pois é de acordo a se esta [direcionalidade] está ou não em conformidade nas diferentes partículas do corpo, que um efeito total maior ou menor pode surgir com relação aos pontos fora do corpo.

Contudo, qualquer que seja a distribuição de magnetismo livre dentro de um corpo, sempre pode-se colocar em seu lugar como resultado de um teorema geral, de acordo com uma lei específica, uma distribuição diferente sobre a superfície do corpo, que exerce exatamente a mesma força externa que a primeira distribuição, de tal forma que um elemento de fluido magnético situado em qualquer lugar do exterior sofre exatamente a mesma atração ou repulsão tanto da distribuição real de magnetismo dentro do corpo, quanto da disbribuição pensada como estando em sua superfície ${ }^{1}$. A mesma ficção pode ser estendida a dois corpos os quais, de acordo com a proporção de magnetismo livre desenvolvida neles, agem um sobre o outro, de tal forma que para cada um deles a distribuição imaginada como sobre suas superficies pode substituir a distribuição interna real. Desta forma pode-se finalmente dar um sentido verdadeiro à maneira usual de falar que, por exemplo, atribui exclusivamente um magnetismo norte a uma extremidade de uma agulha magnetizada, e um magnetismo sul à outra [extremidade], pois é evidente que este modo de falar não está em harmonia com o princípio enunciado acima, o qual é exigido incondicionalmente por outros fenômenos. Mas pode ser suficiente ter dito isto de passagem, discutiremos o próprio princípio mais amplamente numa outra ocasião, pois ele não é necessário para nossos objetivos atuais.

3.

O estado magnético de um corpo consiste na relação da distribuição de magnetismo livre em suas partículas individuais. Com relação à variabilidade deste estado, percebemos uma diferença essencial entre os diferentes corpos magnetizáveis. Em alguns, por exemplo em ferro doce, este estado modifica-se imediatamente como resultado da aplicação da menor força, e se esta força cessa, retorna [o corpo] a seu estado anterior. Em contraste com isto, em outros [corpos], especialmente aço temperado, a força tem de ter atingido uma certa grandeza antes que ela possa gerar uma mudança perceptível no estado magnético, e se esta força cessa, ou o corpo permanece em seu estado transformado, ou ao menos ele não retorna completamente para seu estado anterior. Portanto, em corpos do primeiro tipo as moléculas magnéticas ordenam-se de tal forma que existe um completo equilíbrio entre as forças magnéticas que originam-se parcialmente dos próprios corpos e parcialmente de fontes externas, ou ao menos o estado não diferencia-se apreciavelmente deste que acabamos de descrever. Ao contrário, em corpos do segundo tipo o estado magnético pode ser duradouro mesmo sem haver um equilíbrio completo entre estas forças [magnéticas], desde que forças externas mais fortes permaneçam distantes. Mesmo se a fonte deste fenômeno ainda é desconhecida, ela pode contudo ser representada como se as partes ponderáveis de um corpo do segundo tipo opusessem ao movimento dos fluidos magnéticos associados com elas um obstáculo similar ao atrito, uma resistência que no ferro doce ou é totalmente inexistente ou é apenas muito pequena.

Nas pesquisas teóricas estes dois casos exigem um tratamento totalmente diferente; mas neste tratado lidaremos apenas com corpos do segundo tipo. Nas experiências que queremos mencionar, será uma hipótese fundamental a imutabilidade do estado dos corpos individuais, e portanto tem que se tomar cuidado durante o período das experiências de evitar trazer a uma grande proximidade outros corpos que podem alterar este estado.

Contudo, existe uma fonte certa de mudança em relação à qual os corpos do segundo tipo também estão sujeitos, a saber, o calor. A experiência nos ensina indubitavelmente que o estado magnético de um corpo muda com sua temperatura, contudo de tal forma que, se o corpo não é aquecido imoderadamente, ele retorna a seu estado magnético anterior quando volta à temperatura anterior. Esta dependência

\footnotetext{
${ }^{1}$ Conferir Gauss, Allgemeine Lehrsätze ... (Proposições gerais ...), seção 36. Werke (Obras), vol. V, p. 240 (também Ostwald’s Klassiker (Clássicos de Ostwald), No. 2, p. 49).
} 
é para ser determinada por meio de experiências adequadas, e se são efetuadas observações em temperaturas diferentes como parte de uma experiência, elas serão acima de tudo reduzíveis a uma mesma temperatura.

\section{4.}

Independentemente das forças magnéticas que observamos serem exercidas por corpos entre si que estão suficientemente próximos, uma outra força age sobre os fluidos magnéticos que, como manifesta-se em todos lugares sobre a terra, a atribuímos ao próprio globo e a chamamos de magnetismo terrestre. Esta força expressa-se de forma dual. Corpos do segundo tipo no qual o magnetismo é induzido são, se apoiados no centro de gravidade, girados ao longo de uma direção definida. Em corpos do primeiro tipo, ao contrário, os fluidos magnéticos são automaticamente separados por esta força, uma divisão que pode ser tornada bem perceptível se escolhemos corpos de forma apropriada e os colocamos num local apropriado. Os dois fenômenos são explicados pela interpretação de que num local arbitrário esta força impele o fluido magnético norte numa direção definida e, por outro lado, impele o fluido magnético sul com uma força igual na direção oposta. Sempre é para ser entendida a direção da primeira [força] quando falamos da direção do magnetismo terrestre; portanto ela será determinada tanto pela inclinação em relação ao plano horizontal quanto pelo desvio em relação ao plano meridiano do plano vertical no qual ela age; sendo este chamado de plano meridiano magnético. Contudo, a intensidade do magnetismo terrestre é para ser medida pela força motriz que ela exerce sobre a unidade de fluido magnético livre.

Esta força é não apenas diferente em diferentes lugares sobre a terra, mas também variável no mesmo local ao longo dos séculos e dos anos, assim como ao longo das décadas e das horas. Esta mutabilidade já é de fato há muito tempo conhecida no que diz respeito à direção; mas com relação à intensidade até o momento só foi possível observar isto ao longo das horas de um dia, pois não tínhamos nenhum meio apropriado de observar isto em períodos de tempo maiores. A redução da intensidade a medida absoluta fornecerá no futuro um remédio para esta deficiência.

\section{5.}

Com o objetivo de calcular o efeito do magnetismo terrestre sobre corpos magnéticos do segundo tipo (daqui para a frente estes são os únicos tipos a serem considerados), concebe-se este corpo como dividido em partes infinitesimalmente pequenas; seja $d m$ o elemento de magnetismo livre numa partícula cujas coordenadas em relação a três planos fixos no corpo, perpendiculares entre si, sejam designadas por $x, y, z$. Tomamos os elementos do fluido sul como negativos. Então é claro, inicialmente, que a integral considerada para todo o corpo (e até mesmo para toda parte mensurável do corpo), é dada por $\int d m=0$. Queremos ainda designar $\int x d m=X, \int y d m=Y$ e $\int z d m=Z$, cujas grandezas significam os momentos do magnetismo livre em relação aos três planos ortogonais ou em relação ao eixo

\footnotetext{
${ }^{2}$ Ver Nota 1 de E. Dorn no final deste trabalho.
}

perpendicular a eles. Com a suposição de que $a$ é uma grandeza constante arbitrária, vem que $\int(x-a) d m=X$. Logo é evidente que o momento em relação a um eixo dado depende apenas de sua direção, mas não de sua origem. Se traçamos um quarto eixo através da origem de coordenadas, formando com os três primeiros [eixos] os ângulos $A, B, C$, o momento do elemento $d m$ em relação a este eixo será $=(x \cos A+y \cos B+z \cos C) d m$, e além disto o momento do magnetismo livre no corpo como um todo será

$$
=X \cos A+Y \cos B+Z \cos C=V
$$

Se assumimos que $\sqrt{(X X+Y Y+Z Z)}=M$ e $X=$ $M \cos \alpha ; Y=M \cos \beta ; Z=M \cos \gamma$, e traçamos um quinto eixo formando os ângulos $\alpha, \beta, \gamma$ com os primeiros três eixos, e com o quarto um ângulo $\omega$, então, como uma consequência destas suposições $\cos \omega=\cos A \cos \alpha+$ $\cos B \cos \beta+\cos C \cos \gamma$, vem que $V=M \cos \omega$. Chamamos este quinto eixo simplesmente de eixo magnético do corpo, e assumimos que sua direção é parte do valor positivo da raíz $\sqrt{(X X+Y Y+Z Z)}$. Se o quarto eixo coincide com este eixo magnético, o momento torna-se $V=M$, que é claramente o maior de todos os momentos. O momento em relação a um outro eixo arbitrário é encontrado multiplicando-se este momento máximo (o qual, desde que uma ambiguidade não possa surgir, pode ser chamado simplesmente de momento do magnetismo) pelo co-seno do ângulo entre ele e o eixo magnético. $\mathrm{O}$ momento em relação a um eixo arbitrário perpendicular ao eixo magnético será $=0$, mas será negativo em relação ao eixo que forma um ângulo obtuso com o eixo magnético.

$$
6^{2}
$$

Se uma força com intensidade e direção constante age sobre as partículas individuais do fluido magnético, a força [o torque ou momento] resultante total sobre o corpo pode ser facilmente inferida dos princípios da estática, pois nos corpos em consideração estas partículas perderam seu estado fluido até certo ponto, e formam uma massa presa ao corpo ponderável. Sobre uma partícula magnética arbitrária $d m$ a força motriz $=P d m$ pode agir numa direção $D$ (onde para as moléculas do fluido sul o sinal negativo significa a direção oposta); sejam $A$ e $B$ dois pontos sobre o corpo ao longo da direção do eixo magnético, e seja a distância entre eles $=r$, tomada positivamente quando o eixo magnético está direcionado de $A$ para $B$. Então vê-se facilmente que se duas novas forças são adicionadas a estas forças, cada uma $=\frac{P M}{r}$, das quais uma age sobre $A$ na direção $D$, a outra sobre $B$ na direção oposta, haverá um equilíbrio entre todas estas forças. Portanto as forças anteriores serão equivalentes a duas forças $=\frac{P M}{r}$, das quais uma age sobre $B$ na direção $D$, a outra sobre $A^{r}$ na direção oposta, e claramente estas duas forças não podem ser reunidas numa só.

Se além da força $P$, age uma outra força similar $P^{\prime}$ na direção $D^{\prime}$ sobre os fluidos magnéticos do corpo, então elas podem ser substituídas por duas outras, que agem ou sobre os mesmos pontos $A$ e $B$ ou mais geralmente sobre outros 
pontos $A^{\prime}$ e $B^{\prime}$, desde que $A^{\prime} B^{\prime}$ seja igualmente um eixo magnético e, se a distância for $A^{\prime} B^{\prime}=r^{\prime}$, estas forças têm de ser $=\frac{P^{\prime} M}{r^{\prime}}$, e têm de agir sobre $B^{\prime}$ na direção $D^{\prime}$, sobre $A^{\prime}$ na direção oposta. $\mathrm{O}$ mesmo vale para várias forças.

Pode seguramente ser atribuída à força magnética terrestre [ao campo magnético terrestre], dentro de um espaço tão pequeno como aquele ocupado pelo corpo sujeito à experiência, uma intensidade e direção que são constantes em todos lugares, embora variáveis com o tempo; assim, o que acabamos de dizer pode ser aplicado a ela [força magnética terrestre]. Contudo, pode ser vantajoso separá-la logo de início em duas forças, uma horizontal $=T$ e uma vertical $=T^{\prime}$, a qual em nossa localização é direcionada para baixo. Caso queiramos utilizar em vez da última duas outras agindo sobre os pontos $A^{\prime}$ e $B^{\prime}$, então como é permitível posicionar arbitrariamente o ponto $A^{\prime}$ e também o intervalo $A^{\prime} B^{\prime}$ $=r^{\prime}$, queremos escolher $A^{\prime}$ como o centro de gravidade e, denotando por $p$ ao peso do corpo, isto é a força motriz da gravidade sobre sua massa, dizemos que $\frac{T^{\prime} M}{p}=r^{\prime}$. Por este meio o efeito da força $T^{\prime}$ é decomposto numa força $=p$ direcionada para cima sobre $A^{\prime}$, e numa outra de mesma grandeza direcionada para baixo sobre $B^{\prime}$, e como além disto a primeira é claramente cancelada pela própria força da gravidade, o efeito da componente vertical é reduzido simplesmente a uma transferência do centro de gravidade de $A^{\prime}$ para $B^{\prime}$. Além disto, é claro que para aquelas situações onde a força magnética terrestre forma um ângulo agudo com a força vertical ou, em outras palavras, onde a parte vertical empurra o fluido norte magnético para cima, uma transferência similar do centro de gravidade ocorre para o eixo magnético em direção ao pólo sul.

Nesta maneira de pensar fica auto-evidente que, quaisquer que sejam os tipos de experiências que sejam realizadas com agulhas magnéticas num único estado magnético, é impossível inferir a inclinação apenas a partir daí, mas o centro de gravidade real tem de já ser conhecido de alguma outra forma. Este local é em geral determinado antes da agulha estar magnetizada; mas esta prática não é suficientemente confiável, pois em geral uma agulha de aço já adquire magnetismo, embora fracamente, enquanto está sendo manufaturada. É portanto necessário para a determinação da inclinação induzir uma outra transferência do centro de gravidade por meio de uma alteração apropriada no estado magnético da agulha. Para que este se diferencie tanto quanto possível do primeiro, será necessário reverter os pólos, através do qual é obtida uma transferência dupla. Contudo, mudar o centro de gravidade até mesmo em agulhas que têm a forma mais apropriada e estão saturadas com magnetismo, não pode exceder um certo limite, o qual (para uma transferência simples) é aproximadamente em nossa região igual a $0,4 \mathrm{~mm}$, e em regiões onde a força vertical é máxima fica abaixo de $0,6 \mathrm{~mm}$, e uma precisão mecânica tão grande é necessária na agulha que vai servir para determinar a inclinação.

$$
\text { 7. }{ }^{2)}
$$

Quando qualquer ponto $C$ de um corpo magnético é assumido como estando fixo, a condição necessária e suficiente para o equilíbrio, é que um plano passando por $C$, pelo centro de gravidade e pelo eixo magnético coincida com o meridiano magnético e que, além disto, os momentos com que a força magnética terrestre e o centro de gravidade tentam girar este plano ao redor do ponto $C$, cancelem-se mutuamente. A segunda condição procede do fato que, se $T$ denota a parte horizontal do magnetismo terrestre e $i$ a inclinação do eixo magnético em direção ao plano horizontal, $T M \operatorname{sen} i$ é o produto do peso do corpo na distância do centro de gravidade deslocado $B^{\prime}$ da linha vertical traçada através de $C$. Claramente esta distância tem de estar sobre o lado norte ou sul, dependendo se $i$ é uma elevação ou depressão, e para $i=0, B^{\prime}$ fica sobre a própria linha vertical. Se o corpo já moveu-se ao redor desta linha vertical de tal forma que o eixo magnético atingiu o plano vertical cujo azimute magnético, isto é, seu ângulo com a parte norte do meridiano magnético (considerada arbitrariamente como positiva em direção a leste ou oeste) $=u$, então o magnetismo terrestre exercerá uma força sobre o corpo girando ao redor do eixo vertical, que tenta diminuir o ângulo $u$ e cujo momento será $=T M \cos i$ sen $u$, e o corpo realizará oscilações ao redor deste eixo, cuja duração pode ser calculada de acordo com métodos conhecidos. Ou seja, se $K$ denota o momento de inércia do corpo em relação ao eixo de oscilação (isto é, a soma das moléculas ponderáveis multiplicada pelo quadrado da distância até o eixo) e, como usual, denotamos por $\pi$ à semi-circunferência de raio $=1$, então a duração de uma oscilação infinitamente pequena será

$$
=\pi \sqrt{\frac{K}{T M \cos i}}
$$

ou seja, no caso em que é baseada sobre as grandezas $T$ e $M$ como unidades da força aceleradora, a qual na unidade de tempo produz a velocidade $=1$. A redução de oscilações finitas para infinitamente pequenas é calculável numa maneira similar às oscilações de um pêndulo. Portanto, se a duração de uma oscilação infinitamente pequena é encontrada pelas observações ser $=t$, teremos a equação: $T M=\frac{\pi \pi K}{t t \cos i}$, e quando, além disso, como sempre assumiremos daqui por diante, o corpo está suspenso de tal forma que seu eixo magnético seja horizontal:

$$
T M=\frac{\pi \pi K}{t t} .
$$

Se preferir-se assumir a gravidade como unidade das forças de aceleração, deve-se dividir este valor por $\pi \pi l$, onde $l$ denota o comprimento de um pêndulo de segundos simples, de tal forma que em geral teríamos: $T M=\frac{K}{t t l \cos i}$ ou para nosso caso $T M=\frac{K}{t t l}$.

\section{$8 .^{3)}$}

Quando experiências como estas são realizadas com agulhas magnetizadas suspensas por um fio vertical, então a reação que é exercida pela torção não pode ser desprezada em experiências mais refinadas. Identificamos dois diâmetros horizontais em tal fio, um deles, $D$, na extremidade inferior onde a agulha está presa, paralelo ao eixo magnético da agulha, o outro, $E$, na extremidade superior, 
onde o fio está preso, e de fato $E$ seria paralelo com $D$ se o fio não estivesse torcido. Queremos assumir que $E$ forma um ângulo $v$ com o meridiano magnético, enquanto que $D$, ou o eixo magnético, forma o ângulo $u$ com o meridiano magnético; então a experiência mostra que a torção será proporcional, ao menos aproximadamente, ao ângulo $v--u$. Portanto vamos colocar o momento com o qual esta força tenta tornar o ângulo $u$ igual ao ângulo $v$, como $=(v-u) \Theta$. Como o momento da força magnética terrestre que tenta diminuir o ângulo $u$, é agora $=T M \operatorname{sen} u$, a condição para o equilíbrio está contida na equação: $(v-u) \Theta=T M \operatorname{sen} u$, a qual fornece muitas soluções reais, quão menor seja $\Theta$ em comparação com TM. Contudo, desde que se lide apenas com valores pequenos de $u$, em vez desta equação podese seguramente assumir a seguinte: $(v-u) \Theta=T M u$ ou $\frac{v}{u}=\frac{T M}{\Theta}+1$. Em nosso aparato a extremidade superior do fio está presa a um braço móvel, o qual suporta um indicador marcando sobre a periferia de um círculo dividido em graus. Portanto mesmo se o erro de colimação (isto é, o ponto correspondente ao valor $v=0$ ) não seja conhecido com precisão suficiente, apesar disto este pon- teiro indica a diferença para cada segundo valor de $v$ para frente; assim como uma outra parte do aparato fornece a diferença entre os valores de $u$, correspondendo à condição de equilíbrio com a maior precisão, e fica claro que o valor de $\frac{T M}{\Theta}+1$ será obtido pela divisão da diferença entre dois valores de $v$ pela diferença entre os valores correspondentes de $u$. Se há um período de tempo um pouco maior entre as experiências conduzidas para este fim, será necessário, para atingir uma precisão maior, levar em conta a mudança diária na declinação magnética, o que é facilmente obtido com a ajuda de observações simultâneas num segundo aparato, no qual a extremidade superior do fio permanece inalterada. Quase não é necessario lembrar que a distância entre os dois aparatos tem de ser grande o suficiente para que não possam interferir significativamente um com o outro.

Com o objetivo de mostrar o grande refinamento que estas observações permitem, introduzimos um exemplo do diário. Em 22 de setembro de 1832, salvo o erro de colimação, foram observadas as seguintes declinações $u$ e ângulos $v^{* 3)}$ :

\begin{tabular}{|c|c|c|c|c|}
\hline \multirow{2}{*}{ Experiência } & \multirow{2}{*}{ Tempo } & \multicolumn{2}{|c|}{ Primeira agulha } & \multicolumn{2}{c|}{ Segunda agulha } \\
\cline { 3 - 5 } & & U & $V$ & $U$ \\
\hline I & $9 h$ 33' $\mathrm{Vm}$ & $+0^{\circ} 4^{\prime} 19,5^{\prime \prime}$ & $300^{\circ}$ & $+0^{\circ} 2^{\prime} 12,1^{\prime \prime}$ \\
\hline II & $9 \mathrm{~h} 57^{\prime}$ & $-0^{\circ} 0^{\prime} 19,6^{\prime \prime}$ & $240^{\circ}$ & $+0^{\circ} 11^{\prime} 37,7^{\prime \prime}$ \\
\hline III & $10 \mathrm{~h} 16^{\prime}$ & $-0^{\circ} 4^{\prime} 40,5^{\prime \prime}$ & 180 & $+0^{\circ} 1^{\prime} 18,8^{\prime \prime}$ \\
\hline
\end{tabular}

Portanto as declinações da primeira agulha, relacionadas com a posição da primeira observação, são como segue:

\begin{tabular}{|c|c|c|}
\hline I & $u=0^{\circ} 4^{\prime} 19,5^{\prime \prime}$ & $v=300^{\circ}$ \\
\hline II & $+0^{\circ} 0^{\prime} 14,8^{\prime \prime}$ & $240^{\circ}$ \\
\hline III & $-0^{\circ} 3^{\prime} 47,2^{\prime \prime}$ & $180^{\circ}$ \\
\hline
\end{tabular}

Daqui vem o valor da fração $\frac{T M}{\Theta}$ a partir da combinação das observações

I e II ........... 881,7
II e III ......... 891,5
I e III .......... 8886,6

As mudanças diárias na declinação magnética são diminuídas pela torção na proporção da unidade para $\frac{n}{n+1}$ onde é colocado $\frac{T M}{\Theta}=n$, uma mudança que pode ser considerada insignificante se usamos fios com uma torção tão baixa como mostra o exemplo anterior. No que diz respeito à duração das oscilações (infinitamente pequenas), pode ser facilmente concluído a partir dos princípios dinâmicos, que ela é diminuída pela torção na proporção da unidade para $\sqrt{\frac{n}{n+1}}$. Na realidade, isto relaciona-se ao caso onde $v=0$. Contudo, as fórmulas continuariam válidas em geral se colocássemos $\frac{T M \cos u^{\circ}}{\Theta}=n$ onde denotamos o valor de $u$ por $u^{\circ}$, o qual corresponde ao equilíbrio; mas a diferença será certamente insignificante.
$O$ coeficiente $\Theta$ depende essencialmente do comprimento, da espessura e do material do fio, e adicionalmente em fios metálicos [depende] da temperatura, em fios de seda [depende] da humidade. Em contraste com isto, ele não parece depender no primeiro caso (talvez também no último, se são fios simples) do peso que suportam. A situação é diferente quando os fios de seda são do tipo multiplex, como têm de ser para suportar agulhas pesadas. Neste caso $\Theta$ aumenta com o peso suspenso, contudo permanece bem menor do que o valor de $\Theta$ para um fio metálico com exatamente o mesmo comprimento e capacidade de carga. Assim, através de um método muito similar àquele desenvolvido na seção anterior (embora com um fio diferente e com uma agulha diferente), é encontrado o valor $n=597,4$ enquanto o fio suporta apenas a agulha com o equipamento usual, onde o peso total era de $496,2 g$; em contraste com isto, encontra-se o valor $=424,8$, quando o peso foi aumentado para $710,8 \mathrm{~g}$, ou no primeiro caso foi $\Theta=0,0016740 T M$, no segundo caso $\Theta=0,0023542 T M$. O fio cujo comprimento era de $800 \mathrm{~mm}$, é composto de 32 fios individuais, ${ }^{4}$ os quais individualmente suportam quase $30 \mathrm{~g}$ firmemente e estão arranjados de tal forma que sofrem uma tensão igual. Além disto, é provável que o valor de $\Theta$ seja constituído de um elemento constante e de um elemento proporcional ao peso, e que a parte constante seja igual à soma dos valores de

9.

\footnotetext{
$3 *)$ Ambos elementos crescem da esquerda para a direita.

4 falando estritamente, estes fios não são realmente simples, mas meramente o tipo que é vendido como não fiado.
} 
$\Theta$ para os fios simples individuais. Sob esta hipótese (que até o momento não foi adequadamente confirmada pelas experiências), 0,0001012 TM é encontrado como o valor constante para o exemplo acima, e assim 0,00000316 TM como o valor de $\Theta$ para um fio simples. Utilizando o valor que logo será desenvolvido para $T M$, será calculado a partir desta hipótese que a resistência de um fio simples, enrolado num arco igual ao raio $\left(57^{\circ} 18^{\prime}\right)$, é equivalente à gravidade de uma miligrama pressionando sobre o braço de uma alavanca com o comprimento de aproximadamente $1 / 17 \mathrm{~mm}$.

$$
\text { 10. }{ }^{4)}
$$

Se o corpo oscilante é uma agulha simples de forma regular e massa homogênea, o momento de inércia $K$ pode ser calculado de acordo com métodos conhecidos. Se, por exemplo, o corpo é um paralelepípedo retangular, cujos lados são $a, b, c$, cuja densidade $=d$ e cuja massa $q$ é então $=a b c d$, o momento de inércia em relação a um eixo passando através do ponto médio e paralelo ao lado $c$ será $=\frac{1}{12}(a a+b b) q$. E como em agulhas magnéticas de tal forma o lado que é paralelo ao eixo magnético, a saber $a$, é usualmente bem maior do que $b$, será além disto suficiente para experiências grosseiras tomar $K=\frac{1}{12} \mathrm{aaq}$. Mas em experiências mais refinadas, mesmo se fosse utilizada uma agulha simples, dificilmente poderíamos fazer a suposição confortável de uma massa completamente homogênea e de uma forma completamente regular, e para aquelas experiências nossas nas quais foi utilizada uma agulha envolvendo equipamento mais complicado, em vez de uma agulha simples, é totalmente impossível determinar as coisas através de tais cálculos, e um procedimento diferente foi procurado para a determinação precisa do momento $K$.

$\mathrm{Na}$ agulha foi presa uma barra de madeira transversal sobre a qual pendiam dois pesos iguais através dos quais pontas muito finas exerciam pressões sobre os pontos $A$ e $B$ da barra. Estes pontos estavam sobre uma linha reta horizontal, no mesmo plano vertical que o eixo de suspensão, e estavam equidistantes dele de ambos os lados. Se a massa de cada um dos dois pesos é denotada por $p$ e a distância $A B$ por $2 r$, então ao adicionar este aparato o momento $K$ será aumentado pela grandeza $C+2 p r r$, onde $C$ é a soma do momento da barra em relação ao eixo de suspensão e o momento dos pesos em relação ao eixo vertical através das pontas e do centro de gravidade. Portanto, se são observadas as oscilações da agulha sem os pesos e da agulha pesada em duas distâncias diferentes, a saber, para $r=r^{\prime}$ e $r=r^{\prime \prime}$, e a duração das oscilações (após serem reduzidas a amplitudes infinitamente pequenas e liberadas do efeito da torção) são encontradas, respectivamente, $=t, t^{\prime}, t^{\prime}$, , então combinando as equações:

$$
\begin{gathered}
T M t t=\pi \pi K \\
T M t^{\prime} t^{\prime}=\pi \pi\left(K+C+2 p r^{\prime} r^{\prime}\right) \\
T M t^{\prime \prime} t^{\prime \prime}=\pi \pi\left(K+C+2 p r^{\prime \prime} r^{\prime \prime}\right)
\end{gathered}
$$

podem ser determinadas as três incógnitas $T M, K$ e $C$. Atingiremos uma precisão ainda maior se, para vários valores de $r$, a saber $r=r^{\prime}, r$ ", $r$ "' e assim por diante, observarmos a duração associada das oscilações $t^{\prime}, t^{\prime \prime}, t^{\prime \prime}$, e assim por diante e, de acordo com o método dos mínimos quadrados, determinarmos as duas incógnitas $x$ e $y$ tal que

$$
\begin{aligned}
t^{\prime} & =\sqrt{\frac{r^{\prime} r^{\prime}+y}{x}} \\
t^{\prime \prime} & =\sqrt{\frac{r^{\prime \prime} r^{\prime \prime}+y}{x}} \\
t^{\prime \prime \prime} & =\sqrt{\frac{r^{\prime \prime \prime} r^{\prime \prime \prime}+y}{x}}
\end{aligned}
$$

e assim por diante.

Por este meio obtemos:

$$
\begin{aligned}
& T M=2 \pi \pi p x \\
& K+C=2 p y .
\end{aligned}
$$

Em relação a este método deve ser observado o seguinte:

I. Se é empregada uma agulha não muito lisa, é suficiente colocar simplesmente a barra de madeira sobre ela. Se, contudo, a superfície é muito lisa, de tal forma que o atrito não possa retardar o deslizamento da barra, é necessário conectar a barra mais firmemente ao restante do aparato, de tal forma que o aparato possa mover-se como um corpo sólido único. Em ambos os casos deve ser tomado cuidado para que os pontos $A$ e $B$ estejam localizados com precisão suficiente numa linha reta horizontal.

II. Como o conjunto destas experiências requer várias horas, a variabilidade do magnetismo terrestre dentro deste intervalo de tempo não pode ser desprezada, pelo menos caso se deseje a maior precisão. Portanto, antes que a eliminação seja efetuada, os tempos observados têm de ser reduzidos a um valor constante $T$, por exemplo o valor médio, correspondente à primeira experiência. Para este fim são necessárias observações simultâneas de uma outra agulha (assim como na Seção 8). Se estas observações têm como a duração de uma oscilação para o tempo médio da experiência única, respectivamente, $=u, u$ ', $u$ ”, $u$ "' e assim por diante, então em vez de utilizar para os cálculos os valores observados $t, t^{\prime}, t$ ', $t$ '”, e assim por diante, utiliza-se $\frac{u t^{\prime}}{u^{\prime}}, \frac{u t^{\prime \prime}}{u^{\prime \prime}}, \frac{u t^{\prime \prime \prime}}{u^{\prime \prime \prime}}$, e assim por diante.

III. Vale um comentário similar com relação à variabilidade de $M$, que surge da mudança de temperatura se esta ocorre durante a experiência. Mas é claro que a redução que acabamos de descrever já inclui esta melhoria por si própria, se cada uma das duas agulhas está sujeita à mesma temperatura, e se são influenciadas na mesma maneira por esta mudança.

IV. Se a tarefa é apenas determinar o valor de $T M$, claramente a primeira experiência é supérflua. Contudo será útil associar à experiência conduzida com uma agulha pesada uma outra experiência com uma agulha sem peso, para que o valor de $K$ seja determinado ao mesmo tempo, de tal forma que possa ser tomado como uma base para as experiências que são realizadas numa outra época com a mesma agulha, pois é evidente que este valor permanece constante mesmo quando $T$ e $M$ sofrem uma mudança ao longo do tempo. 
11.

Para explicar melhor este método, incluimos aqui um exemplo da grande quantidade de aplicações. A experiência levada a cabo em 11 de setembro de 1832 forneceu a seguinte tabela:

\begin{tabular}{|c|c|c|c|}
\hline \multirow{2}{*}{ Experiência } & \multicolumn{3}{|c|}{ Oscilações simultâneas } \\
\cline { 2 - 4 } & \multicolumn{2}{|c|}{ da primeira agulha } & da segunda agulha \\
\hline & Peso & Uma oscilação & Uma oscilação \\
\hline I & $r=180 m m$ & $24,63956 ”$ & $17,32191 ”$ \\
\hline II & $r=130 m m$ & $20,77576 ”$ & $17,32051 ”$ \\
\hline III & $r=80 m m$ & $17,66798 ”$ & $17,31653 "$ \\
\hline IV & $r=30 m m$ & $15,80310 "$ & $17,30529 "$ \\
\hline V & Sem peso & $15,22990 "$ & $17,31107 ”$ \\
\hline
\end{tabular}

Os tempos foram observados num relógio que diariamente perdia 14,24 " do tempo médio, e cada um dos dois pesos era de 103,2572 $\mathrm{g}$; as distâncias $r$ em milímetros foram determinadas com precisão microscópica; a duração de uma oscilação, que foi apurada a partir de no mínimo 100 oscilações (na quinta experiência até mesmo para 677 para a primeira agulha), já foi reduzida para arcos infinitamente pequenos. Além disto, estas reduções eram insignificantes devido à amplitude tão pequena das oscilações ${ }^{5}$ que são possíveis aplicar em nosso aparato sem detrimento da maior precisão. Queríamos reduzir estes tempos de oscilação em primeiro lugar ao valor médio de $T M$, que ocorreram durante a quinta experiência aplicando as regras da Seção II acima; então aos valores que teriam resultado sem torção através da multiplicação por $\sqrt{\frac{n+1}{n}}$ onde $n$ nas quatro experiências $=$ 424,8 , na quinta experiência $=597,4$ (conferir Seção 9); finalmente ao tempo solar médio através da multiplicação por $\frac{864,00}{86385,76} ;$ nossos resultados foram:

$$
\begin{aligned}
& \text { I. } 24,65717 "=t \text { para } r=180 \mathrm{~mm} \\
& \text { II. } 20,79228 "=t " \text { para } r "=130 \mathrm{~mm} \\
& \text { III. } 17,68610 "=t ", \text { para } r ",=80 \mathrm{~mm} \\
& \text { IV. } 15,82958 "=t ", \text { para } r ",=30 \mathrm{~mm}
\end{aligned}
$$

V. $15,24515 "=t$ para a agulha sem peso.

Se tomamos o segundo, o milímetro e o miligrama como unidades de tempo, distância e massa, de tal forma que $p=$ 103257,2, inferimos da combinação da primeira experiência com a quarta:

$\mathrm{TM}=179641070 ; \mathrm{K}+\mathrm{C}=4374976000$

e então da quinta experiência

$K=4230282000$ e similarmente $C=144694000$.

Quando, contudo, é desejado levar em consideração todas as experiências, o método dos mínimos quadrados é o mais conveniente da forma seguinte. Procedemos a partir dos valores aproximados das incógnitas $x$ e $y$, que surgem da combinação da primeira e da quarta experiências e, designando as correções ainda a serem adicionadas por $\xi$ e $\eta$, dizemos:

$$
\begin{aligned}
& x=88,13646+\xi \\
& y=21184,85+\eta .
\end{aligned}
$$

A partir daqui são derivados como valores calculados os tempos $t^{\prime}, t$,', $t$,', $t$,"’ por métodos familiares:

$$
\begin{aligned}
& t^{\prime}=24,65717-0,13988 \xi+0,00023008 \eta \\
& t^{\prime \prime}=20,78731-0,11793 \xi+0,00027291 \eta \\
& t^{\prime \prime \prime}=17,69121-0,10036 \xi+0,00032067 \eta \\
& t^{\prime \prime \prime \prime}=15,82958-0,08980 \xi+0,00035838 \eta
\end{aligned}
$$

cuja comparação com os valores observados, tratados de acordo com o método dos mínimos quadrados, gera os resultados:

$$
\begin{aligned}
& \xi=-0,03230 ; \eta=-12,38 \\
& x=88,10416 ; y=21172,47 .
\end{aligned}
$$

A partir disto resulta finalmente

$$
T M=179575250, K+C=4372419000,
$$

e então com a adição da primeira experiência:

$$
K=4228732400, C=143686600 .
$$

Apresento a seguir uma comparação dos tempos calculados a partir dos valores corrigidos das grandezas $x, y, \mathrm{com}$ os valores observados.

\footnotetext{
${ }^{5}$ Assim a amplitude das oscilações na primeira experiência era de $0^{\circ} 37$ '26” no início, 0 `28’34" no fim; na quinta experiência $1{ }^{\circ} 10^{\prime} 21^{\prime \prime}$ no início,

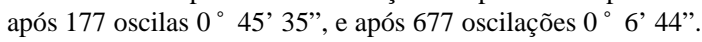




\begin{tabular}{|c|c|c|c|}
\hline Experiência & Tempo calculado & Tempo observado & Diferença \\
\hline I & $24,65884{ }^{\prime}$ & 24,65717 & $+0,00167$ \\
\hline II & 20,78774 & 20,79228 & $-0,00454$ \\
\hline III & 17,69046 & 17,68610 & $+0,00436$ \\
\hline IV & 15,82805 & 15,82958 & $-0,00153$ \\
\hline
\end{tabular}

Em Göttingen colocamos o comprimento de um pêndulo de segundos simples $=994,126 \mathrm{~mm}$, portanto o peso, medido por aquela unidade das forças de aceleração na qual é baseada os cálculos precedentes, $=9811,63$; assim se preferimos tomar a própria gravidade como unidade, então $T M$ $=18302,29$. Este número expressa o número de miligramas cuja pressão sob a influência da gravidade numa alavanca com comprimento de um milímetro é equivalente à força com que o magnetismo terrestre tenta girar esta agulha ao redor do eixo vertical.

\section{2.}

Após termos completado a determinação do produto da componente horizontal $T$ da força magnética terrestre com o momento magnético $M$ da agulha dada, procedemos para a segunda parte da experiência, a saber, para a determinação da razão $M / T$. Obteremos isto comparando o efeito desta agulha sobre uma outra agulha, com o efeito do magnetismo terrestre sobre a mesma agulha. Especificamente isto será observado, como já foi discutido na introdução, ou num estado de movimento ou num estado de equilíbrio. Investigamos repetidamente cada um dos dois métodos, mas por vários motivos o último é muito preferível ao primeiro. E assim confinaremos as investigações aqui a este último, sendo que o primeiro pode ser tradado de maneira similar sem dificuldade.

13.

As condições de equilíbrio num corpo móvel sobre o qual agem forças arbitrárias, podem ser facilmente juntadas numa única fórmula por meio do princípio dos deslocamentos virtuais. A saber, a soma dos produtos de uma força qualquer multiplicada na projeção de um pequeno deslocamento infinitesimal de seu ponto de atuação na direção da força, tem de ser constituída de tal forma que para nenhum movimento virtual (isto é, um movimento condizendo com as condições) ela possa atingir um valor positivo, de tal forma que se os movimentos virtuais são possíveis coletivamente em direções opostas, este agregado, que queremos designar por $d \Omega$, é $=0$ para todo movimento virtual.

O corpo móvel que consideramos aqui é a agulha magnética, que é conectada num ponto $G$ a um fio giratório preso no alto. Este fio meramente evita que a distância do ponto $G$ até a extremidade fixa do fio torne-se maior do que o comprimento do fio, de tal forma que aqui também, assim como no caso do corpo completamente livre, a posição do corpo no espaço depende de seis variáveis e além disto o próprio equilíbrio de seis condições. Contudo, como a solução do problema é apenas para determinar a razão $M / T$, é suficiente considerar o movimento virtual que ocorre na rotação ao redor do eixo vertical intersectando $G$; e é evidente que tal eixo pode ser considerado como fixo, e apenas o ângulo entre o plano vertical sobre o qual está localizado o eixo magnético, e o plano meridiano magnético, como variável. Tomaremos este ângulo a partir do lado norte do meridiano em direção ao leste e o designaremos por $u$.

14.

Conceberemos o volume da agulha magnética móvel como dividido em elementos infinitamente pequenos, deixando as coordenadas de um elemento arbitrário serem $x, y, z$, enquanto que $e$ é o elemento de magnetismo livre contido nele. Colocamos a origem das coordenadas no ponto arbitrário $h$ dentro da agulha sobre uma linha vertical passando através de $G$; o eixo das coordenadas $x$ e $y$ é para ser horizontal, o primeiro no meridiano magnético direcionado em direção ao norte, o último em direção a leste; a coordenada $z$ consideramos como acima. Então o efeito do magnetismo terrestre sobre o elemento $e$ gera o elemento $T e d x$ de $d \Omega$.

De forma similar, o volume da segunda agulha fixa é dividido em elementos infinitamente pequenos, e um elemento qualquer corresponde às coordenadas $X, Y, Z$, e a quantidade $E$ de magnetismo livre; finalmente, seja $r=$ $\sqrt{(X-x)^{2}+(Y-y)^{2}+(Z-z)^{2}}$. Sob esta condição, o efeito do elemento $E$ sobre o elemento $e$ gera a contribuição $\frac{e E d r}{r^{n}}$ para a soma $d \Omega$, se a potência $r^{n}$ da distância $r$ é assumida como sendo inversamente proporcional. Se denotamos por $N$ ao valor de $u$ que corresponde ao estado do fio não torcido, então o momento de torção do fio pode ser expresso como $\Theta(N-u)$. Esta força pode ser concebida de tal forma como se a força tangencial $=\frac{\Theta(N-u)}{D}$ agisse sobre cada extremidade de um diâmetro horizontal do fio passando através de $G$, onde $D$ denota este diâmetro, e vêse facilmente que a partir daqui como elemento da soma $d \Omega$ é derivado: $\Theta(N-u) d u$.

O peso das partículas da agulha claramente não contribui para a soma $d \Omega$, pois apenas $u$ é variável; portanto temos a equação:

$$
d \Omega=\sum T e d x+\sum \frac{e E d r}{r^{n}}+\Theta(N-u) d u
$$

na qual a soma no primeiro termo relaciona-se com todos elementos $e$, no segundo com todas as combinações dos $e$ individuais com os $E$ individuais. Portanto fica claro que a condição de equilíbrio consiste em

$$
\Omega=\sum T e x-\sum \frac{e E}{(n-1) r^{n-1}}-\frac{1}{2} \Theta(N-u)^{2}
$$

tornar-se um máximo. 
15.

É conveniente para nosso propósito sempre construir as experiências de tal forma que o eixo magnético de cada uma das duas agulhas seja horizontal, e que ambas as agulhas estejam aproximadamente na mesma altura; portanto desejamos confinar nossos próximos cálculos a estas precondições.

Queremos relacionar as coordenadas dos pontos da primeira agulha a eixos fixos na agulha, que também ainda intersectam o ponto $h$; isto é, o primeiro eixo estaria na direção do eixo magnético, o segundo horizontal e à direita do primeiro, o terceiro vertical e apontando para cima; as coordenadas do elemento $e$ em relação a estes eixos são $a, b, c$. De forma semelhante $A, B, C$ são as coordenadas do elemento $E$ em relação a eixos similarmente fixados na segunda agulha, que intersectam esta agulha num ponto $H$. Selecionamos este ponto próximo ao centro da agulha e à mesma altura que o ponto $h$.

A posição do ponto $H$ seria é claro determinada mais convenientemente pela distância do ponto $h$ e a direção da linha reta associada com ela, se a questão é de apenas uma experiência. Como, contudo, para nossos fins são necessárias sempre várias experiências, que estão relacionadas a posições diferentes do ponto $H$, todas as quais estando certamente na mesma linha reta, contudo não necessariamente numa linha através do ponto $h$, é melhor construir a demonstração desde o início de tal forma que o sistema de tais experiências dependa de uma única incógnita. Portanto queremos relacionar o ponto $H$ a um ponto arbitrário $h^{\prime}$ no mesmo plano horizontal, que está próximo de $h$ e cujas coordenadas possam ser $\alpha, \beta, 0$, e desejamos tornar a distância $h^{\prime} H=R$ e o ângulo das linhas $h^{\prime} H$ com o meridiano magnético $=\psi$. Se agora denotamos o ângulo do eixo magnético da segunda agulha com o meridiano magnético por $U$, então teremos:

$$
\begin{aligned}
& x=a \cos u-b \operatorname{sen} u \\
& y=a \operatorname{sen} u+b \cos u \\
& y=c \\
& X=\alpha+R \cos \psi+A \cos U-B \operatorname{sen} U \\
& Y=\beta+R \operatorname{sen} \psi+A \operatorname{sen} U+B \cos U \\
& Z=C .
\end{aligned}
$$

Assim tudo está pronto para desenvolver a soma $\Omega$ e a fração $\frac{d \Omega}{d u}$, a qual tem de desaparecer no estado de equilíbrio.

16.

Inicialmente teremos $\sum T e x=T \cos u \sum a e-$ $T \operatorname{sen} u \sum b e=m T \cos u$, se denotamos por $m$ ao momento do magnetismo livre da primeira agulha $\sum a e$, pois $\sum b e=0$. O elemento de $\frac{d \Omega}{d u}$, que deriva do primeiro termo de $\Omega$, será $=-m T \operatorname{sen} u$.

Se colocamos para simplificar:

$$
\begin{aligned}
& k=\alpha \cos \psi+\beta \operatorname{sen} \psi+A \cos (\psi-U)+B \operatorname{sen}(\psi-U)-\alpha \cos (\psi-u)-b \operatorname{sen}(\psi-u) \\
& l=[\alpha \operatorname{sen} \psi-\beta \cos \psi+A \operatorname{sen}(\psi-U)-B \cos (\psi-U)-a \operatorname{sen}(\psi-u)-b \cos (\psi-u)]^{2}+(C-c)^{2}
\end{aligned}
$$

então teremos $r r=(R+k)^{2}+l$.

Como nas experiências úteis $R$ tem de ser muito maior do que as dimensões de cada uma das agulhas, a grandeza $\frac{1}{r^{n-1}}$ pode ser desenvolvida numa série rapidamente convergente

$$
R^{-(n-1)}-(n-1) k R^{-n}+\left(\frac{n n-n}{2} k k-\frac{n-1}{2} l\right) R^{-(n+1)}-\left(\frac{1}{6}\left(n^{3}-n\right) k^{3}-\frac{1}{2}(n n-1) k l\right) R^{-(n+2)}+\ldots
$$

cuja lei, se valesse à pena o esforço, poderia ser facilmente especificada. Os termos individuais da soma $\sum \frac{e E}{r^{n-1}}$, que surgem ao se inserir os valores das grandezas $k$ e $l$, conterá um fator da forma:

$$
\sum e E a^{\lambda} b^{\mu} c^{\nu} A^{\lambda^{\prime}} B^{\mu^{\prime}} C^{\nu^{\prime}}
$$

isto é igual ao produto dos fatores $\sum e a^{\lambda} b^{\mu} c^{\nu}$ e $\sum E A^{\lambda^{\prime}} B^{\mu^{\prime}} C^{\nu^{\prime}}$, que dependem respectivamente do estado magnético da primeira e da segunda agulhas. Levando isto em consideração, o que podemos estabelecer confina-se às equações:

$$
\begin{aligned}
& \sum e=0, \quad \sum e a=m, \sum e b=0, \quad \sum e c=0, \\
& \sum E=0, \quad \sum E A=M, \quad \sum E B=0, \quad \sum E C=0,
\end{aligned}
$$

onde denotamos por $M$ ao momento do magnetismo livre da segunda agulha. No caso especial em que a forma da primeira agulha (a móvel) e em que a distribuição do magnetismo na direção longitudinal são simétricos, de tal forma que dois elementos sempre se correspondam, para os quais $a$ e $e$ tenham valores opostos equivalentes $b$ e $c$, então, tão logo os pontos médios coincidam com o ponto $h$, sempre teremos $\sum e a^{\lambda} b^{\mu} c^{\nu}=0$ para um valor direto do número $\lambda+\mu+\nu$, e similarmente para a segunda agulha, se a forma e a distribuição do magnetismo são simétricos em relação ao ponto $H$. Portanto, em geral, na soma $\sum \frac{e E}{r^{(n-1)}}$ os coeficientes das potências $R^{-(n-1)}$ e $R^{-n}$ desaparecem; no caso especial em que cada uma das duas agulhas tem o formato simétrico e estão simetricamente magnetizadas, enquanto que ao mesmo tempo o ponto médio da primeira, $h$ e $h^{\prime}$, coincidem, e de forma semelhante o ponto médio da segunda e $H$ coincidem, então os coeficientes das potências $R^{-(n+2)}, R^{-(n+1)}, R^{-(n+6)}$ e assim por diante também vao desaparecer; todas as vezes em que estas condições 
ocorrem de forma bem aproximada, estes coeficientes têm de ser ao menos muito pequenos. O termo principal que é derivado pela elaboração do segundo elemento de $\Omega$, a saber de

$$
-\sum \frac{e E}{(n-1) r^{(n-1)}}
$$

será:

$$
\begin{aligned}
& =-\frac{1}{2} R^{-(n+1)}\left(n \sum e E k k-\sum e E l\right) \\
& =m M R^{-(n+1)}(n \cos (\psi-U) \cos (\psi-u)-\operatorname{sen}(\psi-U) \operatorname{sen}(\psi-u)) .
\end{aligned}
$$

Daqui segue-se que o elemento de $\frac{d \Omega}{d u}$, que corresponde à influência da segunda agulha, pode ser expresso pela seguinte série:

$$
f R^{-(n+1)}+f^{\prime} R^{-(n+2)}+f^{\prime \prime} R^{-(n+3)}+\ldots,
$$

na qual os coeficientes contêm funções racionais do co-seno e do seno dos ângulos $\psi, u, U$ e as grandezas são $\alpha, \beta$, e além disto contêm magnitudes constantes que dependem do estado magnético da agulha; especificamente, eles serão:

$$
\begin{aligned}
f= & m M(n \cos (\psi-U) \operatorname{sen}(\psi-u) \\
& +\operatorname{sen}(\psi-U) \cos (\psi-u)) .
\end{aligned}
$$

A elaboração completa dos coeficientes seguintes $f^{\prime}, f^{\prime \prime}$ e assim por diante não é necessária para nossos fins; é suficiente notar que

1) no caso de simetria completa, os coeficientes que acabamos de indicar $f^{\prime}, f^{\prime \prime}$ e assim por diante desaparecem;

2) se as magnitudes restantes permanecem inalteradas e $\psi$ é aumentado de dois ângulos retos (ou, a mesma coisa, se a distância $R$ é considerada ao longo da mesma linha reta prolongada para trás sobre o outro lado do ponto $h^{\prime}$ ), os coeficientes $f, f$ ", $f$ " " e assim por diante mantêm seus valores, enquanto que $f^{\prime}, f$ "', $f$ ", ', e assim por diante ficam com valores opostos, ou esta série transforma-se em

$$
f R^{-(n+1)}-f^{\prime} R^{-(n+2)}+f^{\prime \prime} R^{-(n+3)}-\ldots ;
$$

isto é inferido facilmente do fato que por meio desta mudança em $\psi, k$ torna-se $-k$, mas $l$ não é transformada.

\section{7. ${ }^{5)}$}

A condição para que a agulha móvel não gire ao redor do eixo vertical pela combinação das forças é então resumida na seguinte equação:

$$
\begin{aligned}
0= & -m T \operatorname{sen} u+f R^{-(n+1)}+f^{\prime} R^{-(n+2)} \\
& +f^{\prime \prime} R^{-(n+3)}+\ldots-\Theta(u-N) .
\end{aligned}
$$

Como pode ser facilmente efetuado que o valor de $N$, se não é $=0$, é ao menos muito pequeno, e também $u$, na experiência que está sendo considerada, permanece dentro de valores estreitos, então, sem temer um erro significativo, para o termo $\Theta(u-N)$ pode-se usar $\Theta \operatorname{sen}(u-N)$, ainda mais que $\frac{\Theta}{m T}$ é uma fração muito menor. Seja $u^{\circ}$ o valor de $u$ que corresponde ao equilíbrio da primeira agulha na ausência da segunda, ou seja

$$
m T \operatorname{sen} u^{\circ}+\Theta \operatorname{sen}\left(u^{\circ}-N\right)=0
$$

daqui segue-se facilmente que:

$$
\begin{gathered}
m T \operatorname{sen} u+\Theta \operatorname{sen}(u-N)= \\
\left(m T \cos u^{\circ}+\Theta \cos \left(u^{\circ}-N\right)\right) \operatorname{sen}\left(u-u^{\circ}\right),
\end{gathered}
$$

onde, em vez do primeiro fator pode-se adotar $m T+\Theta$ sem maiores reservas. Assim nossa equação torna-se:

$$
\begin{gathered}
(m T+\Theta) \operatorname{sen}\left(u-u^{\circ}\right)= \\
f R^{-(n+1)}+f^{\prime} R^{-(n+2)}+f^{\prime \prime} R^{-(n+3)}+\ldots .
\end{gathered}
$$

Se mantemos apenas o termo $f R^{-(n+1)}$ então a solução fica ao alcance da mão, a saber, temos

$$
\operatorname{tg}\left(u-u^{\circ}\right)=\frac{m M\left(n \cos (\psi-U) \operatorname{sen}\left(\psi-u^{\circ}\right)+\operatorname{sen}(\psi-U) \cos \left(\psi-u^{\circ}\right)\right) R^{-(n+1)}}{m T+\Theta+m M\left(n \cos (\psi-U) \cos \left(\psi-u^{\circ}\right)-\operatorname{sen}(\psi-U) \operatorname{sen}\left(\psi-u^{\circ}\right)\right) R^{-(n+1)}}
$$

onde no denominador do elemento que contem o fator $R^{-(n+1)}$, podemos suprimir ou afirmar com a mesma correção:

$$
\operatorname{tg}\left(u-u^{\circ}\right)=\frac{m M}{m T+\Theta}\left(n \cos (\psi-U) \operatorname{sen}\left(\psi-u^{\circ}\right)+\operatorname{sen}(\psi-U) \cos \left(\psi-u^{\circ}\right)\right) R^{-(n+1)}=F R^{-(n+1)} .
$$


Contudo, quando queremos levar em consideração termos adicionais, então é claro que $t g\left(u-u^{\circ}\right)$ pode ser desenvolvida numa série da seguinte forma:

$\operatorname{tg}\left(u-u^{\circ}\right)=F R^{-(n+1)}+F^{\prime} R^{-(n+2)}+F^{\prime \prime} R^{-(n+3)}+\ldots$,

na qual, como mostra uma simples reflexão, os coeficientes $F, F$, $F$ ', e assim por diante até os coeficientes da potência $R^{-(2 n+1)}$, respectivamente, resultam inclusivamente de

$$
\frac{f}{m T+\Theta}, \frac{f^{\prime}}{m T+\Theta}, \frac{f^{\prime \prime}}{m T+\Theta}, \text { e assim por diante, }
$$

através da mudança de $u$ em $u^{\circ}$; do termo seguinte em diante, contudo, novos elementos entrarão, os quais para nossos fins não precisamos determinar mais precisamente.
Além disto, é claro que $u-u^{\circ}$ pode ser desenvolvido numa

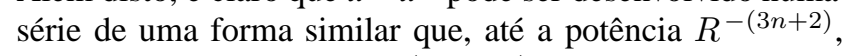
coincide com a série para $\operatorname{tg}\left(u-u^{\circ}\right)$.

$$
18 .^{6}
$$

É agora claro que, se a segunda agulha é colocada em pontos diferentes sobre a mesma linha reta, de tal forma que $\psi$ e $U$ mantêm seus valores, enquanto que apenas $R$ é modificado, e é observado o desvio da agulha móvel a partir da posição de equilíbrio, por meio da qual a segunda agulha é deslocada, a saber, o ângulo $u-u^{\circ}$, daqui segue-se que os valores dos coeficientes $F, F^{\prime}, F^{\prime \prime}$ e assim por diante, tantos quantos ainda sejam significativos, podem ser apurados por eliminação; por este meio obteremos a equação:

$$
\frac{M}{T}=\left(1+\frac{\Theta}{T m}\right) \frac{F}{n \cos (\psi-U) \operatorname{sen}\left(\psi-u^{\circ}\right)+\operatorname{sen}(\psi-U) \cos \left(\psi-u^{\circ}\right)}
$$

na qual o valor da grandeza $\frac{\Theta}{T m}$ pode ser obtido pelo método que demonstramos na Seção 8. Para uma demonstração mais conveniente, contudo, será útil observar o seguinte:

I. Em vez da comparação de $u \operatorname{com} u^{\circ}$ é preferível comparar os dois desvios opostos entre si revertendo a posição da segunda agulha, a saber, de tal forma que $R$ e $\psi$ permaneçam inalterados e o ângulo $U$ seja aumentado em dois ângulos retos. Se os valores de $u$ correspondendo a estas posições são denotados por $u^{\prime}$ e $u^{\prime \prime}$, então no caso de simetria completa teremos precisamente $u^{\prime \prime}=-u^{\prime}$, se ao mesmo tempo valesse $u^{\circ}=0$. Mas é supérfluo ficar ansiosamente preso a estas condições, pois é claro que $u^{\prime}$ e $u^{\prime \prime}$ são determinados por séries similares nas quais os primeiros termos têm precisamente valores opostos, e além disto também $\frac{1}{2}\left(u^{\prime}-u^{\prime \prime}\right)$, assim como $\operatorname{tg} \frac{1}{2}\left(u^{\prime}-u^{\prime \prime}\right)$ por uma série similar, na qual o coeficiente do primeiro termo é precisamente $=F$.

II. Será ainda melhor sempre combinar todas as quatro experiências, também depois do ângulo $\psi$ ser modificado por dois ângulos retos ou a distância $R$ ter sido tomada sobre o outro lado. Se as duas últimas experiências correspondem aos valores $u^{\prime \prime \prime}$ e $u^{\prime \prime \prime \prime}$, então a diferença $\frac{1}{2}\left(u^{\prime \prime \prime}-u^{\prime \prime \prime \prime}\right)$ será expressa por uma série similar, cujo primeiro termo similarmente terá um coeficiente $=F$. Deve ser notado (o que segue prontamente do que veio antes) que, se $n$ fosse um número ímpar, os coeficientes $F, F$, $F$ ”, , e assim por diante seriam exatamente os mesmos até o infinito em qualquer série para $u^{\prime}-u^{\circ}$ e $u^{\prime \prime},-u^{\circ}$, e os coeficientes $F^{\prime}, F^{\prime}$, ', $F$ ",' e assim por diante seriam precisamente opostos até o infinito, e o mesmo para $u^{\prime \prime}--u^{\circ}$ e $u$ "” $-u^{\circ}$, de tal forma que na série para $u$ ' $-u$ " $+u$ "' $-u$ ", os termos alternados desapareceriam. Mas no caso da realidade, onde $n=2$, em geral não está estritamente presente tal relação entre as séries para $u^{\prime}--u^{\circ}$ e para $u$ "' $-u^{\circ}$ pois para a potência $R^{-6}$, já surgem coeficientes que não são precisamente opostos. Contudo, pode ser mostrado que também para este termo ocorre um cancelamento completo na combinação $u$ ' - $u$ ” $+u$ "' - $u$ ",', de tal forma que $\operatorname{tg} \frac{1}{4}\left(u^{\prime}-u^{\prime \prime}+u^{\prime \prime \prime}-u^{\prime \prime \prime \prime}\right)$ fica com a forma:

$$
L R^{-3}+L^{\prime} R^{-5}+L^{\prime \prime} R^{-7}+\ldots
$$

ou, mais geralmente, se deixamos o valor de $n$ indeterminado por hora, a seguinte forma:

$$
L R^{-(n+1)}+L^{\prime} R^{-(n+3)}+L^{\prime \prime} R^{-(n+5)}+\ldots,
$$

onde $L=F$.

III. Será útil escolher os ângulos $\psi$ e $U$ de tal forma que pequenos erros ocorrendo no próprio processo de medida não mudem significativamente o valor de $F$. Para este fim o valor de $U$ para um dado valor de $\psi$ tem de ser assumido de tal forma que $F$ seja um máximo; isto é, tem de ser

$$
\operatorname{ctg}(\psi-U)=n \operatorname{tg}\left(\psi-u^{\circ}\right)
$$

Então

$$
F= \pm \frac{m M}{m T+\Theta} \sqrt{\left(n n \operatorname{sen}\left(\psi-u^{\circ}\right)^{2}+\cos \left(\psi-u^{\circ}\right)^{2}\right)}
$$

Contudo, o ângulo $\psi$ é para ser escolhido tal que este valor de $F$ seja ou um máximo ou um mínimo. O primeiro caso ocorre para $\psi-u^{\circ}=90^{\circ}$ ou $270^{\circ}$, sendo que neste caso $F= \pm \frac{n m M}{m T+\Theta}$, o último caso ocorre para $\psi-u^{\circ}=0$ ou $180^{\circ}$, onde $F= \pm \frac{m M}{m T+\Theta}$.

\footnotetext{
${ }^{6}$ Ver Nota 5 de E. Dorn, final.
} 
Portanto dois métodos estão disponíveis, os quais são os mais apropriados para realizar nossa tarefa. Seus elementos são mostrados no esquema seguinte.
O ponto médio e o eixo da segunda agulha estão sobre a linha reta perpendicular ao meridiano magnético ${ }^{7}$.

\begin{tabular}{|c|c|c|c|c|}
\hline Deflexão & \multicolumn{2}{|c|}{ Posição da agulha } & Ponto médio em direção ao & Pólo norte em direção ao \\
\hline$u=u$ & $\psi=90^{\circ}$ & $\mathrm{U}=90^{\circ}$ & Leste & Leste \\
\hline$u=u "$ & $\psi=90$ & $U=270$ & Leste & Oeste \\
\hline$u=u^{\prime \prime}$ & $\psi=270$ & $U=90$ & Oeste & Leste \\
\hline$u=u^{\prime \prime \prime}$ & $\psi=270$ & $U=270$ & Oeste & Oeste \\
\hline
\end{tabular}

Segundo método.

O ponto médio da segunda agulha está sobre o meridiano magnético.

\begin{tabular}{|c|c|c|c|c|}
\hline Deflexão & \multicolumn{2}{|c|}{ Posição da agulha } & Ponto médio em direção ao & Pólo norte em direção ao \\
\hline$u=u$ & $\psi=0^{\circ}$ & $\mathrm{U}=270^{\circ}$ & Norte & Oeste \\
\hline$u=u ”$ & $\psi=0$ & $U=270$ & Norte & Leste \\
\hline$u=u^{\prime \prime}$ & $\psi=180$ & $U=90$ & Sul & Oeste \\
\hline$u=u ’ "$ & $\psi=180$ & $U=90$ & Sul & Leste \\
\hline
\end{tabular}

Se colocamos $\frac{1}{4}\left(u^{\prime}-u^{\prime \prime}+u^{\prime \prime \prime}-u^{\prime \prime \prime \prime}\right)=v$ e $\operatorname{tg} v=$ $L R^{-(n+1)}+L^{\prime} R^{-(n+3)}+L^{\prime \prime} R^{-(n+5)}+$ e assim por diante, então para o primeiro método

$$
L=\frac{n m M}{m T+\Theta},
$$

para o segundo

$$
L=\frac{m M}{m T+\Theta} .
$$

20.

A partir da teoria de eliminação será facilmente concluído que o cálculo torna-se mais impreciso devido aos erros inevitáveis de observação quanto maior for o número de coeficientes que têm de ser determinados por eliminação. Portanto o método prescrito na Seção 18, II, é para ser altamente apreciado por ele suprimir os coeficientes $R^{-(n+2)}$, $R^{-(n+4)}$. No caso de simetria completa estes coeficientes já seriam eliminados por si mesmos, mas seria muito incerto depender da ocorrência deste caso. Além disto, um pequeno desvio da simetria teria uma influência muito menor no primeiro método do que no segundo, e se ao menos é tomado cuidado para que o ponto $h^{\prime}$, a partir do qual são medidas as distâncias, esteja com precisão suficiente no meridiano magnético passando através do ponto $h$, não haverá diferença significativa entre $u^{\prime}-u^{\prime \prime}$ e $u$ "' - $u$ ”, '. Contudo, as coisas ficam diferentes no segundo método, especialmente se o aparato requer suspensão excêntrica. Este método sempre atingirá uma precisão muito menor sempre que o espaço não permitir observações de ambos os lados. Além disto, o primeiro método é também especialmente preferível por permitir um valor de $L$ duas vezes tão grande quanto no segundo, no caso da realidade, onde $n=2$. Se, a propósito, queremos descartar, tanto quanto possivel no segundo método, o termo dependente de $R^{-(n+2)}$ no caso de suspensão excêntrica, o ponto $h^{\prime}$ deve ser escolhido de tal forma que o ponto médio da agulha (para $u-u^{\circ}$ ) esteja no centro entre $h$ e $h^{\prime}$. Contudo, devo omitir o cálculo que mostrou isto por questão de brevidade.

21.

Nos cálculos anteriores deixamos o expoente $n$ indeterminado. Durante os dias de 24 de junho a 28 de junho de 1832, realizamos duas séries de experiências com extenções até as maiores distâncias permitidas pela sala, através das quais mostra-se mais inteligivelmente quais valores exige a natureza. Na primeira série a segunda agulha (de acordo com o método da Seção 19) foi colocada numa linha reta perpendicular ao meridiano magnético, na segunda série o ponto médio da agulha foi ele próprio colocado no meridiano. Aqui vai um panorama destas experiências, nas quais as distâncias $R$ estão expressas em frações de metros e os valores do ângulo $\frac{1}{4}\left(u^{\prime}-u^{\prime \prime}+u^{\prime \prime \prime}-u^{\prime \prime \prime \prime}\right)$ estão denotados para a primeira série por $v$, e para a segunda série por $v^{\prime}$.

\footnotetext{
${ }^{7}$ Mais precisamente, sobre o plano vertical, que corresponde ao valor $u=u^{\circ}$, isto é, no qual o eixo magnético encontra-se em equilíbrio quando a segunda agulha não está presente. Para o restante, na prática, a diferença pode seguramente ser ignorada, tanto por causa do tamanho pequeno e principalmente por causa da relação que discutimos na Seção III acima.
} 


\begin{tabular}{|c|c|c|}
\hline$R$ & $v$ & $v^{\prime}$ \\
\hline $1,1 \mathrm{~m}$ & & $1^{\circ} 57^{\prime} 24,8^{\prime \prime}$ \\
\hline 1,2 & & 12940,5 \\
\hline 1,3 & $2^{\circ} 13^{\prime} 51,2^{\prime}$ & 11019,3 \\
\hline 1,4 & 14728,6 & 05558,9 \\
\hline 1,5 & 12719,1 & 04514,3 \\
\hline 1,6 & 1127,6 & 03712,2 \\
\hline 1,7 & 109,9 & 03057,9 \\
\hline 1,8 & 05052,5 & 02559,5 \\
\hline 1,9 & 04321,8 & 0229,2 \\
\hline 2,0 & 03716,2 & 0191,6 \\
\hline 2,1 & 0324,6 & 01624,7 \\
\hline 2,5 & 01851,9 & 0936,1 \\
\hline 3,0 & 0110,7 & 0533,7 \\
\hline 3,5 & 0656,9 & 0328,9 \\
\hline 4,0 & 0435,9 & 0222,2 \\
\hline
\end{tabular}

Mesmo uma olhada superficial mostra que para valores maiores os números na segunda coluna são aproximadamente duas vezes tão grandes quanto os números da terceira, e também os números em cada coluna seguem aproximadamente o inverso do cubo da distância, de tal forma que nenhuma dúvida permanece em relação à precisão do valor $n=2$. Para confirmar ainda mais esta lei através de experiências específicas lidamos com todos os números de acordo com o método dos mínimos quadrados, através do qual surgiram os seguintes valores dos coeficientes:

$$
\begin{aligned}
& t g v=0,086870 R^{-3}-0,002185 R^{-5} \\
& t g v^{\prime}=0,043435 R^{-3}+0,002449 R^{-5} .
\end{aligned}
$$

O resumo seguinte mostra a comparação dos valores calculados por esta fórmula com os valores observados.

\begin{tabular}{|c|c|c|c|c|}
\hline \multicolumn{5}{|c|}{ Valores calculados. } \\
\hline$R$ & $v$ & Diferença & $v^{\prime}$ & Diferença \\
\hline $1,1 \mathrm{~m}$ & & & $1^{\circ} 57^{\prime} 22,0^{\prime \prime}$ & $+2,8^{\prime}$ \\
\hline 1,2 & & & 12946,5 & $-6,0$ \\
\hline 1,3 & $2^{\circ} 13^{\prime} 50,4^{\prime \prime}$ & $+0,8^{\prime \prime}$ & 11013,3 & $+6,0$ \\
\hline 1,4 & 14724,1 & $+4,5$ & 05558,7 & $+0,2$ \\
\hline 1,5 & 12728,7 & $-9,6$ & 04520,9 & $-6,6$ \\
\hline 1,6 & 11210,9 & $-3,3$ & 03715,4 & $-3,2$ \\
\hline 1,7 & 1014,9 & $-5,0$ & 03059,1 & $-1,2$ \\
\hline 1,8 & 05048,3 & $+4,2$ & 0262,9 & $-3,4$ \\
\hline 1,9 & 04314,0 & $+7,8$ & 0226,6 & $+2,6$ \\
\hline 2,0 & 0375,6 & $+10,6$ & 01855,7 & $+5,9$ \\
\hline 2,1 & 0323,7 & $+0,9$ & 01619,8 & $+4,9$ \\
\hline 2,5 & 0192,1 & $-10,2$ & 0938,6 & $-2,5$ \\
\hline 3,0 & 0111,8 & $-1,1$ & 0533,9 & $-0,2$ \\
\hline 3,5 & 0657,1 & $-0,2$ & 0329,8 & $-1,0$ \\
\hline 4,0 & 0439,6 & $-3,7$ & 0220,5 & $+1,7$ \\
\hline
\end{tabular}

22.

As experiências precedentes foram realizadas principalmente com a intenção de colocar a lei de ação magnética acima de qualquer suspeita e, além disto, de examinar quantos termos da série são para ser levados em conta, assim como saber o grau de precisão que as experiências permi- tem. Elas mostraram que, se não fazemos as distâncias menores do que quatro vezes o comprimento da agulha, dois termos são suficientes ${ }^{8}$. Além disto, as diferenças que o cálculo produziu não podem simplesmente ser devidas a erros observacionais. Várias medidas preventivas ainda não estavam prontas na época, com a aplicação de-

\footnotetext{
${ }^{8} \mathrm{O}$ comprimento das agulhas utilizadas nestas experiências era de aproximadamente $0,3 \mathrm{~m}$; se tivéssemos tentado incluir o termo $R^{7}$ no cálculo, a precisão teria diminuído em vez de aumentar.
} 
las pode ser esperado uma conformidade maior. Estas incluem correções para a variabilidade horária da intensidade do magnetismo terrestre, para a qual deve-se levar em consideração a utilização de uma outra agulha para comparação, de acordo com o método do qual falamos na Seção 10. Contudo, para que possamos saber o valor do magnetismo terrestre, até onde pode ser obtido por estas experiências, acrescentamos uma sinopse das experiências restantes neste grupo.

$\mathrm{O}$ valor da fração $\frac{\Theta}{T m}$ para a primeira agulha e para o fio sobre o qual ela está pendurada, é obtido pelo método descrito na Seção 8 como sendo $=\frac{1}{251,96}$.

Daqui vem o resultado:

$$
\frac{M}{T}=0,0436074
$$

Este número é baseado no metro como unidade de comprimento. Se preferimos considerar o milímetro, este número deve ser multiplicado pelo cubo de 1000 , de tal forma que

$$
\frac{M}{T}=43607400
$$

Para a segunda agulha, experiências foram efetuadas em 28 de junho assemelhando-se àquelas que descrevemos para uma outra agulha na Seção 11; milímetros, miligramas e os segundos do tempo solar médio foram tomados como unidades, resultando em:

$$
T M=135457900,
$$

e a partir disto, por eliminação da grandeza $M$,

$$
T=1,7625 \text {. }
$$

23.

Se são realizadas experiências para determinar o valor absoluto $T$ do magnetismo terrestre, é muito significativo tomar cuidado que o conjunto destas experiências seja completado dentro de um intervalo de tempo não muito longo, de tal forma que não se receie uma mudança significativa no estado magnético das agulhas utilizadas nas experiências. É recomendado que ao observar os desvios da agulha móvel seja aplicado apenas o procedimento na Seção 20, após apenas duas distâncias diferentes terem sido escolhidas apropriadamente, assumindo que dois termos da série sejam suficientes. Escolhemos como exemplo uma entre as várias aplicações deste método, a saber, aquela para a qual foi devotado o maior cuidado ao medir-se as distâncias com precisão microscópica.

As experiências foram efetuadas em 18 de setembro de 1832 com dois aparatos que queremos denotar por $A$ e $B$, e especificamente com três agulhas, denotadas por 1, 2, 3 . As agulhas 1 e 2 são as mesmas referidas como a primeira e a segunda na Seção 11. As experiências são divididas em duas partes.

Inicialmente foram observadas as oscilações simultâneas da agulha 1 no aparato $A$ e da agulha 2 no aparato $B$. Resultaram como duração de uma oscilação, reduzida a amplitudes infinitamente pequenas:

$$
\begin{aligned}
& \text { para a agulha } 1 \ldots . . .15,22450 " \\
& \text { para a agulha } 2 \ldots \ldots . .17,29995 ",
\end{aligned}
$$

a primeira para 304 oscilações, a última para 264 oscilações.

Em seguida a agulha 3 foi suspensa no aparato A, enquanto a agulha 1 era colocada na linha reta perpendicular ao meridiano magnético, direcionada ao leste e também ao oeste e em ambos os lados numa maneira dupla, e foi observado o desvio da agulha 3 para a posição única da agulha 1. Esta experiência, que foi repetida para duas distâncias diferentes $R$, deu os seguintes valores do ângulo $v$, cujo significado é o mesmo que na Seção 19 e na Seção 21:

\begin{tabular}{|c|c|}
\hline$R=1,2 m$ & $v=3^{\circ} 42^{\prime} 19,4{ }^{\prime \prime}$ \\
\hline$R^{\prime}=1,6 m$ & $v^{\prime}=1^{\circ} 34^{\prime} 19,33^{\prime \prime}$ \\
\hline
\end{tabular}

Também durante esta experiência foram observadas as oscilações da agulha 2 no aparato $B$. O tempo médio calculado para 414 oscilações correspondeu ao valor da duração da oscilação para arcos infinitamente pequenos $=17,29484$.

Os períodos de tempo foram observados num relógio cujo atraso diário era de 14,24 ". Se $M$ e $m$ denotam o momento do magnetismo livre para as agulhas 1 e 3 , e $\Theta$ a constante de torção do fio no aparato $A$, enquanto suporta a agulha 1 ou a 3 (cujo peso é quase idêntico), então temos:

$$
\frac{\Theta}{T M}=\frac{1}{597,4},
$$

como na Seção 11,

$$
\frac{\Theta}{T m}=\frac{1}{721,6}
$$

pois a agulha 3 estava mais fortemente magnetizada do que a agulha 1 .

O momento de inércia da agulha 1 já era conhecido de experiências anteriores (ver a Seção 11), que haviam fornecido: $K=4228732400$, onde foram utilizados o milímetro e o miligrama como unidades.

A mudança no termômetro em ambas as salas onde foram instalados os aparatos foi tão pequena durante todo o período das experiências que é supérfluo considerá-la aqui.

Queremos agora proceder ao cálculo destas experiências com o objetivo de inferir delas a intensidade $T$ do magnetismo terrestre. A variação nas oscilações da agulha 2 indicam uma mudança pequena nesta intensidade. Portanto, para que possamos falar de um valor definido, vamos reduzir a duração observada das oscilações da primeira agulha ao estado médio do magnetismo terrestre durante a segunda parte das observações. Esta duração requer ainda uma outra redução devido ao atraso do relógio, e uma terceira devido à torção do fio. Desta forma a duração reduzida de uma oscilação produziu: 


$$
=15,22450 \times \frac{17,29484}{17,29995} \cdot \frac{86400}{86385,76} \cdot \sqrt{\frac{598,4}{597,4}}=15,23500^{\prime \prime}=t .
$$

Daqui segue o valor do produto

$$
T M=\frac{\pi \pi K}{t t}=179770600 .
$$

A pequena diferença entre este valor e aquele na Seção 11 encontrado em 11 de setembro é para ser atribuído a mudança no magnetismo terrestre e também a mudança no estado magnético da agulha.

Dos desvios observados derivamos:

$$
F=\frac{R^{\prime 5} t g v^{\prime}-R^{5} t g v}{R^{\prime} R^{\prime}-R R}=113056200
$$

se consideramos o milímetro como unidade, e portanto

$$
\frac{M}{T}=\frac{1}{2} F\left(1+\frac{\Theta}{T m}\right)=56606437
$$

Finalmente, a comparação deste número com o valor de $T M$ produz

$$
T=1,782088
$$

como valor da intensidade da força magnética [do campo magnético] terrestre horizontal em 18 de setembro às 5 horas.

$$
24 .
$$

As experiências precedentes foram feitas no observatório onde a localização para o aparato foi procurada de tal forma que o ferro fosse mantido longe de suas proximidades tanto quanto possível. Contudo, não pode ser duvidado que massas de ferro exerceram um efeito de forma alguma insignificante sobre as agulhas suspensas, massas estas que estavam distribuídas abundantemente nas paredes, janelas e portas do prédio, na verdade, até as componentes de ferro dos grandes instrumentos astronômicos, sendo que nestas massas o magnetismo é induzido pela força magnética terrestre. As forças surgindo daqui alteram não apenas a direção mas também a intensidade do magnetismo terrestre num pequeno valor, e nossas experiências não fornecem o valor puro da intensidade do magnetismo terrestre, mas o valor modificado pelo local do aparato $A$. Desde que as massas de ferro permaneçam em seus lugares e os elementos do próprio magnetismo terrestre (a saber, a intensidade e a direção) não modifiquem-se muito consideravelmente, esta modificação tem de permanecer significativamente constante, mas qual magnitude é alcançada é de fato desconhecida até agora; todavia, estou ligeiramente inclinado a acreditar que ela excede em um ou dois centésimos do valor total. Contudo, não deve ser difícil determinar as grandezas através de experiências, ao menos aproximadamente, a saber, através da observação das oscilações simultâneas de duas agulhas, das quais uma estaria no local usual de observação, a outra neste meio tempo numa distância bem grande do prédio e de outras massas de ferro perturbadoras, as quais teriam então de trocar de lugar. Mas até o momento não foi possível realizar esta experiência. O remédio mais seguro, contudo, é construir um prédio especial devotado a observações magnéticas, o qual será logo construído como resultado da graça real, sendo que em sua construção o ferro é para ser totalmente excluído.

\section{5.}

Além das experiências descritas, realizamos muitas outras experiências similares, mesmo que tenhamos tomado menos cuidado do que nas anteriores. Todavia, será de interesse juntar aqui os resultados numa tabela na qual, contudo, estes resultados são transitórios, os quais antes da instalação do aparato mais refinado, foram obtidos através de outros, com recursos mais toscos em agulhas das mais variadas dimensões, embora todos eles tenham fornecido pelo menos uma aproximação da realidade. Através de experiências repetidas resultaram os seguintes valores sucessivos de $T$ :

\begin{tabular}{|c|c|c|}
\hline Número & Época, 1832 & $\mathrm{T}$ \\
\hline I & Maio 21 & 1,7820 \\
\hline II & Maio 24 & 1,7694 \\
\hline III & Junho 4 & 1,7713 \\
\hline IV & Junho 24-28 & 1,7625 \\
\hline V & Julho 23, 24 & 1,7826 \\
\hline VI & Julho 25, 26 & 1,7845 \\
\hline VII & Setembro 9 & 1,7764 \\
\hline VIII & Setembro 18 & 1,7821 \\
\hline IX & Setembro 27 & 1,7965 \\
\hline X & Outubro 15 & 1,7860 \\
\hline
\end{tabular}

As experiências V-IX foram realizadas juntas no mesmo local, mas as I-IV em locais diferentes; a experiência X é de fato uma mistura, pois os desvios foram observados no lugar usual, mas as oscilações num outro local. Nas experiências VII e VIII, foi aplicada uma precisão quase idêntica; contudo, nas experiências IV, V, VI e X, uma precisão um pouco menor, e nas experiências I-III uma muito menor. Nas experiências I-VIII, de fato, foram utilizadas agulhas diferentes, embora tivessem o mesmo peso e o mesmo comprimento (o peso estava entre $400 \mathrm{~g}$ e $440 \mathrm{~g}$ ); a experiência 
$\mathrm{X}$, ao contrário, utilizou uma agulha cujo peso era de 1062 $g$ e cujo comprimento era de $485 \mathrm{~mm}$. A experiência IX só foi realizada para determinar qual grau de precisão pode ser obtido através de uma agulha muito pequena. $\mathrm{O}$ peso da agulha empregada era de apenas $58 \mathrm{~g}$, contudo, além disto a precisão não era muito menor do que nas experiências VII eVIII. Não há dúvida que será significativamente aumentado o refinamento destas observações quando forem empregadas agulhas ainda mais pesadas, por exemplo agulhas pesando até 2000 ou $3000 \mathrm{~g}$.

26.

Se a intensidade $T$ do magnetismo terrestre é para ser expressa por um número $k$, então este é baseado numa certa unidade $V$, a saber, uma idêntica com aquela força, cuja conexão com as outras unidades dadas diretamente está certamente contida na acima, mas numa forma um pouco complicada. Portanto, valerá à pena demonstrar esta conexão aqui novamente, para mostrar com clareza elementar que mudança sofre o número $k$, se começamos com outras unidades em vez das unidades originais.

Para estabelecer a unidade $V$, tem-se de proceder da unidade de magnetismo livre $M^{9}$ e da unidade de distância $R$, e fazemos $V$ igual à força exercida por $M$ na distância $R$.

Como unidade $M$, assumimos aquela quantidade de fluido magnético que exerce, numa quantidade igualmente grande $M$ na distância $R$, uma força motriz (ou, caso prefira-se, uma pressão), que é equivalente a este $W$ que serve como unidade, isto é, equivalente à força que atua sobre a massa $P$ suposta unitária com uma aceleração $A$ suposta unitária.

Para estabelecer a unidade $A$, estão disponíveis dois caminhos. A saber, $A$ pode ou ser derivada a partir de uma força dada imediatamente similar, por exemplo a partir da gravidade no local da observação, ou do efeito de $A$, o qual manifesta-se no movimento dos corpos. O segundo método, o qual seguimos em nossos cálculos, requer duas novas unidades, a saber, a unidade de tempo $S$ e a unidade de velocidade $C$, de tal forma que a aceleração que é considerada como unitária é aquela que, se age no tempo $S$, produz a velocidade $C$; finalmente, assumimos para a última velocidade aquela que corresponde ao movimento uniforme através do espaço $R$ no tempo $S$.

Assim é claro que a unidade $V$ depende de três unidade, ou $R, P, A$ ou $R, P, S$.

Se agora em lugar das unidades $V, R, M, W, A, P, C, S$, assumimos outras: $V^{\prime}, R^{\prime}, M^{\prime}, W^{\prime}, A^{\prime}, P^{\prime}, C^{\prime}, S^{\prime}$, que estão conectadas entre si como as anteriores, e o magnetismo terrestre é expresso pelo número $k^{6}$ pelo emprego das medidas $V^{\prime}$, então é para ser investigado como este $\left[k^{\bullet}\right]$ relaciona-se $\operatorname{com} k$.

Se dizemos:

$$
\begin{gathered}
V=v V^{\prime} \\
R=r R^{\prime} \\
M=m M^{\prime}
\end{gathered}
$$

$$
\begin{aligned}
& W=w W^{\prime} \\
& A=a A^{\prime} \\
& P=p P^{\prime} \\
& C=c C^{\prime} \\
& S=s S^{\prime},
\end{aligned}
$$

então $v, r, m, w, a, p, c, s$ serão números absolutos e

$$
\begin{aligned}
& k V=k^{\prime} V^{\prime} \text { ou } k v=k^{\prime}, \\
& v=\frac{m}{r r}, \\
& \frac{m m}{r r}=w=p a, \\
& a=\frac{c}{s}, \\
& c=\frac{r}{s} .
\end{aligned}
$$

Da combinação destas equações encontramos:

$$
\begin{array}{|c|l|}
\hline \text { I. } & k^{\prime}=k \sqrt{\frac{p}{r s s}} \\
\hline \text { II. } & k^{\prime}=k \sqrt{\frac{p a}{r r}} . \\
\hline
\end{array}
$$

Desde que sigamos o caminho utilizado em nossas observações, somos obrigados a utilizar esta primeira fórmula. Se, por exemplo, assumimos o metro e a grama como unidades em vez do milímetro e da miligrama, então $r=\frac{1}{1000}, p=\frac{1}{1000}$, portanto $k=k^{\prime}$; se a linha de Paris e o arrátel de Berlin [são utilizados como unidades] então teremos: $r=\frac{1}{2,255829}, p=\frac{1}{467711,4}$, consequentemente

$$
k^{\prime}=0,002196161 k
$$

e assim, por exemplo, a experiência VIII fornece o valor $T$ $=0,0039131$.

Se preferimos seguir um outro caminho e assumimos a gravidade como unidade da força aceleradora então, para o observatório de Göttingen, $a=\frac{1}{9811,63}$; então, se mantemos o milímetro e o miligrama, os números $k$ são para ser multiplicados por 0,01009554 e a alteração da unidade anterior é para ser tratada de acordo com a fórmula II.

A intensidade da força magnética terrestre horizontal $T$ é para ser multiplicada pela secante da inclinação com o objetivo de obter-se a intensidade total. Foi mostrado pelas observações de Humboldt o fato de que a inclinação é variável em Göttingen e que esta sofreu uma diminuição no período recente, sendo que ele encontrou no mês de dezembro de 1805 o valor 69 ${ }^{\circ} 29^{\prime}$, mas no mês de setembro de 1826 encontrou $68^{\circ} 29^{\prime} 26^{\prime}$ ". De forma semelhante encontrei em 23 de junho de 1832, com ajuda do mesmo aparelho para medir as inclinações que Mayer empregou, $68^{\circ} 22^{\prime}$ 52", o que parece indicar um retardo no declínio; contudo estou inclinado a dar um valor menor a esta observação, não apenas devido à imperfeição do instrumento, mas também devido à circunstância de que a observação realizada no observatório não estava protegida adequadamente da influência das massas de ferro. Contudo, estes fatores também ganharão uma precisão maior no futuro.

\footnotetext{
${ }^{9}$ Quase não é necessário lembrar que cessa aqui a notação anterior dada para as letras.
} 
28.

Neste tratado seguimos a maneira usualmente adotada de explicar os fenômenos magnéticos, não apenas por ela ser completamente adequada, mas também devido a ela levar a cálculos bem mais simples do que a outra maneira, que atribui o magnetismo a correntes galvano-elétricas ao redor das partículas do corpo magnético. Não foi nossa intenção confirmar nem refutar esta visão que com certeza recomenda-se em diversos aspectos; isto seria inoportuno, pois a lei do efeito mútuo entre os elementos de tais correntes ainda não parece ter sido investigada suficientemente. Qualquer que seja a visão adotada no futuro para os fenômenos, sejam eles puramente magnéticos ou eletromagnéticos, a primeira teoria [das correntes] tem de sempre levar aos mesmos resultados que a teoria usual. E o que está desenvolvido com base na teoria usual no presente tratado, estará numa posição de ser modificado apenas na forma, mas não no essencial.

Notas relativas ao artigo " $\mathrm{A}$ intensidade da força magnética terrestre reduzida a medida absoluta", de C. F. Gauss. Notas escritas por E. Dorn em Halle, datadas de 22/09/1893. Referência original: C. F. Gauss, Die Intensität der Erdmagnetischen Kraft auf Absolutes Maass zurückgeführt (Wilhelm Engelmann Verlag, Leipzig, 1894), E. Dorn (editor), Ostwald's Klassiker der Exakten Wissenschaften, Número 53.

O tratado de Gauss cuja tradução está publicada tem por diversos motivos um significado extraordinário para a física: através do novo princípio de medida das grandezas físicas (o assim chamado sistema de medidas absoluto ${ }^{10}$, se obtem a possibilidade de determinar com sua ajuda a intensidade do magnetismo terrestre a qualquer momento numa medida invariável e finalmente através de novos métodos de observação com uma precisão até então inalcansável.

$\mathrm{Na}$ mecânica analítica já era comum a longo tempo se derivar as unidades para as grandezas mecânicas restantes a partir das unidades básicas para comprimento, massa e tempo (para Gauss estas eram $m m, m g, s$; após a resolução do Congresso de Paris de 1881 elas são agora $\mathrm{cm}, \mathrm{g}, \mathrm{s}$ ). Como unidade de velocidade vale aquela pela qual a unidade de comprimento é percorrida na unidade de tempo; a unidade de aceleração acontece então quando a velocidade cresce na unidade de velocidade que acaba de ser definida no tempo 1; a unidade de força motriz é aquela que confere a aceleração 1 à massa 1 .
Gauss $^{11}$ ampliou este procedimento para além do campo da mecânica pura: baseado na lei de interação de Coulomb entre dois pólos magnéticos, definiu ele como unidade de magnetismo à quantidade de magnetismo Norte [pólo magnético Norte] que exerce numa outra quantidade igual a esta separada pela unidade de distância a força absoluta medida 1, e estabeleceu como unidade da intensidade magnética (a magnitude do campo magnético) à que atua com força 1 na unidade de pólo.

O próprio Gauss ${ }^{12}$ já havia chamado a atenção que, não haveria nenhuma dificuldade de se reduzir também as medidas galvânicas a medidas absolutas", e seu amigo e colaborador Wilhelm Weber ${ }^{13}$ resolveu de fato este problema, ao mesmo tempo que estabeleceu o sistema de medidas eletromagnético absoluto.

Atribui-se atualmente para as unidades derivadas certas "dimensões" com relação às unidades básicas, por exemplo se $l, m, t$ indicam as unidades básicas, coloca-se como dimensão de velocidade $l t^{-1}$, e similarmente para um pólo magnético $l^{3 / 2} m^{1 / 2} t^{-1}$, para um campo magnético $l^{-1 / 2} m^{1 / 2} t^{-1} .^{14} \mathrm{O}$ principiante deve ser advertido do malentendido de considerar as dimensões como o significado verdadeiro das grandezas respectivas e de querer considerar um pólo magnético equivalente a $l^{3 / 2} m^{1 / 2} t^{-1}$. Gauss não forneceu nenhum motivo para este mal-entendido, muito pelo contrário expôs claramente o verdadeiro sentido do que hoje chamamos de dimensões, que as mesmas meramente possuem significado para a passagem de um sistema de unidades básicas para um outro. A saber, se adota-se em lugar das unidades $l, m, t$ novas unidades $l^{\prime}, m^{\prime}, t^{\prime}$, as quais relacionam-se com as antigas por $l=\lambda l^{\prime}, m=\mu m^{\prime}, t=$ $\tau t^{\prime}$, então por exemplo o número que expressa a intensidade horizontal [do campo magnético terrestre] no sistema $l, m, t$ é para ser multiplicado por $\lambda^{-1 / 2} \mu^{1 / 2} \tau^{-1}$ para se encontrar o número que representa a mesma grandeza no novo sistema. Assim atualmente no meio da Alemanha a intensidade horizontal nas unidades Gaussianas $m m, m g, s$ é de cerca de 1,9. Se quisermos passar para o sistema $\mathrm{cm}, \mathrm{g}, \mathrm{s}$ então como $1 \mathrm{~mm}=0,1 \mathrm{~cm}$ e $1 \mathrm{mg}=0,001 \mathrm{~g}$ temos de multiplicar 1,9 por $0,1^{-1 / 2} \cdot 0,001^{1 / 2}=0,1$, com o que se obtem 0,19 .

Sem dúvida já resulta do fato de que existem dois ${ }^{15}$ sistemas de medidas elétricos nos quais as mesmas grandezas possuem dimensões bem diferentes que as dimensões das grandezas no sistema de medidas absoluto não indicam o verdadeiro significado das mesmas, isto também já resulta por mostrar-se que quase todas as grandezas físicas expressam-se através de comprimento, massa e tempo.

A opinião sobre o sistema de medida absoluto passou por muitas mudanças no decorrer do tempo; após um período de sobrestimação parece que agora caímos no erro oposto.

\footnotetext{
${ }^{10}$ Uma descrição coerente do sistema de medidas absoluto encontra-se por exemplo em F. Kohlrausch, Leitfaden der praktischen Physik (Manual de Física Prática), Apêndice.

${ }^{11}$ Ver Seção 26.

${ }^{12}$ Anúncio lido em Göttingen em 24 de dezembro de 1832. Gauss, Werke (Obras), Vol. V, p. 301.

${ }^{13}$ W. Weber, Werke (Obras), Vol. III, págs. 6, 276, 320, 591.

${ }^{14}$ Comparar Gauss, Seção 26. A teoria das "dimensões" foi desenvolvida inicialmente por Fourier para o ramo do calor. Ver Fourier, Théorie Analytique de la Chaleur (Teoria Analítica do Calor). §159-162. 1822.

${ }^{15}$ Ou até mesmo quatro. Comparar Hertz, Wied. Ann. 24, p. 114, 1885.
} 
Em primeiro lugar assegura a aplicação das medidas absolutas - o que para o ramo do magnetismo ainda vai ser discutido pormenorizadamente mais para a frente - uma possibilidade de comparação das medidas que foram realizadas em épocas diferentes e em lugares diferentes. Além disso a expressão de muitas leis naturais assume uma forma muito simples quando certos fatores tornam-se iguais a 1 (por exemplo a força entre dois pólos magnéticos $\mu_{1}$ e $\mu_{2}$ separados pela distância $r$ torna-se igual a $\left.\frac{\mu_{1} \mu_{2}}{r^{2}}\right)$ e particularmente a unidade de "energia" para o ramo da eletricidade e do magnetismo torna-se análoga à unidade de energia mecânica.

Estas vantagens tiveram como consequência que, como na última década a eletrotécnica desenvolveu-se imensamente, seus representantes unanimemente adotaram o sistema de unidades baseado nas medidas eletromagnéticas absolutas.

Uma tentativa notável de transformação e de desenvolvimento adicional do sistema de medidas absoluto foi empreendido recentemente por W. Ostwald ${ }^{16}$. Suas sugestões positivas dependem em essência, em primeiro lugar em introduzir para os diversos ramos como unidades básicas comuns o comprimento, tempo e energia (em lugar do significado apenas limitado que possui a massa).

Para a mecânica bastam estas unidades; para todo outro ramo - eletricidade, magnetismo, calor, energia radiante, química - precisa-se ainda de estabelecer uma quarta, para cada ramo respectivo uma unidade especial.

Percebe-se que por esse meio torna-se possível a aplicação de medidas absolutas também para os fenômenos de calor, da energia radiante e das forças químicas - o que não deu resultado pelo caminho preparado por Gauss e Weber.

Porém para o magnetismo resulta por aqui uma dificuldade particular.

Aparentemente a quarta unidade de Ostwald, se é para ser útil na prática, tem de permanecer imutável (como o metro original) ou tem de ser sem dúvida reproduzível (como a unidade de resistência de Siemens).

Contudo não há um íma imutável nem um lugar de intensidade imutável do magnetismo terrestre, de tal forma que a sugestão de Ostwald torna-se impraticável, se nos limitamos apenas ao magnetismo.

Levando em conta a eletricidade o problema torna-se solúvel: após a determinação da medida elétrica ${ }^{17}$ toma-se como unidade do momento magnético (o "magnetismo de barra") aquele que a grande distância exerce um efeito igual que uma corrente de grandeza 1 fluindo na unidade de área.

Para se apreciar adequadamente o significado do trabalho de Gauss para o nosso conhecimento do magnetismo terrestre, em especial de sua intensidade, tem de se ter presente o estado deste ramo da ciência antes de sua publicação ${ }^{18}$. Antes de Gauss podia-se (através da observação das oscilações de uma agulha magnética, especialmente de uma agulha de inclinação) obter uma comparação bem grosseira da intensidade presente em um lugar com a presente em um outro lugar normal. Contudo, devido às mudanças que acontecem [no campo magnético terrestre e no momento magnético da agulha], estas comparações em intervalos de tempo maiores perdem todo o valor. Gauss mostrou como determinar a intensidade usando a todo momento uma medida inalterável; ele a designou como "absoluta" em oposição às medidas relativas anteriores. Ele não contentouse de empregar seu método em Göttingen, mas fundou a Sociedade Magnética de vasta ramificação, cujas valiosas observações ele publicou em associação com Weber ${ }^{19}$.

Gauss refere-se a um trabalho de Poisson ${ }^{20}$; contudo estaria-se enganado caso se considerasse este como inventor do sistema de medida absoluto. Poisson mostra que quando a unidade de magnetismo [pólo magnético] exerce a força $f$ numa outra [unidade] igual separada pela unidade de distância, a intensidade do magnetismo terrestre pode ser expressa com ajuda de $f$. O método sugerido para isto são as oscilações de duas agulhas magnéticas apenas sob a influência do magnetismo terrestre e então cada agulha sob a influência conjunta da outra e do magnetismo terrestre.

Nota-se que Poisson deixa como arbitrária a unidade de magnetismo, enquanto que o cerne do sistema de medida absoluta de Gauss repousa justamente em determinar a mesma pelo efeito da força.

Para o aperfeicoamento dos métodos de observação ${ }^{21}$ os quais a propósito não estão descritos neste tratado - foi de auxílio para Gauss suas qualidades como astrônomo prático. Pode-se considerar como fundamentos de uma grande parte da arte de observação moderna as medidas de ângulo inventadas por Gauss ${ }^{22}$, e experimentadas pela primeira vez com as medidas do magnetismo terrestre, realizadas com telescópio, espelho e escala, assim como suas prescrições para determinar o período de oscilação de um íma e para a obtenção empírica de seu momento de inércia.

\section{Sobre a Seção 6.}

Para os iniciantes não serão supérfluos alguns esclarecimentos.

A força magnética possui direção e intensidade constantes, (o campo magnético é homogêneo“) na parte do espaço em consideração aqui.

É introduzido um sistema de coordenadas fixo $x y z$ no espaço; que na unidade de magnetismo (comparar Seção 26) a força ativa $\Re$ [o campo magnético $\Re$ ] tem as componentes

\footnotetext{
${ }^{16}$ W. Ostwald, Studien zur Energetik (Estudos sobre Energética), Ber. d. Sächs. Ges. d. Wissenschaften, 1891, p. 271 , e 1892, p. 211.

${ }^{17}$ Esta é realizável de diversas maneiras.

${ }^{18}$ Pode-se ver a introdução do próprio Gauss. As observações de Humboldt lá citadas acham-se em Gilbert's Ann. Vol. 7, p. 329, 1801, e Vol. 20, p. 257, 1805; as de Sabine em Pogg. Ann. Vol. 6, p. 88, 1826.

${ }^{19}$ Resultate aus den Beobachtungen des magnet. Vereins (Resultados das observações da Sociedade Magnética), 1836-1841 [pode-se também traduzir Magnetischer Verein por Associação ou União Magnética].

${ }^{20}$ Poisson, Solution d'un problème relatif au magnétisme terrestre (Solução de um problema relativo ao magnetismo terrestre). Connaissance des temps, 1828 , p. 322.

${ }^{21}$ Comparar Resultate aus den Beobachtungen des magnetischen Vereins, especialmente 1836, p. 13.

22 e independentemente por Poggendorf.
} 
$X, Y, Z^{23}$, de tal forma que as componentes da força translatória atuando numa partícula magnética $\mu$ são dadas por

$$
\mu X, \mu Y, \mu Z,
$$

e para o íma inteiro

$$
\sum \mu X, \sum \mu Y, \sum \mu Z
$$

Porém como $X, Y, Z$ são constantes e $\sum \mu=0$, vem que esta grandeza $=0$, e num campo magnético homogêneo não atua nenhuma força translatória. Portanto só pode haver um momento de torção.

Sejam $x, y, z$ as coordenadas de $\mu$, assim resulta ter o momento de torção ao redor do eixo $x$ o valor

$$
\mathcal{M}_{x}=\sum(y \cdot \mu Z-z \cdot \mu Y)=Z \sum \mu y-Y \sum \mu z .
$$

Colocando-se

$$
\sum \mu x=\alpha, \quad \sum \mu y=\beta, \quad \sum \mu z=\gamma,
$$

então

$$
\mathcal{M}_{x}=\beta Z-\gamma Y \text { e similarmente }
$$

$$
\mathcal{M}_{y}=\gamma X-\alpha Z
$$

$$
\mathcal{M}_{z}=\alpha Y-\beta X
$$

As grandezas $\alpha, \beta, \gamma$ são os momentos [magnéticos] do íma na direção dos eixos $x, y, z$.

Denota-se por $M$ o momento principal do íma, e seja este entendido ao mesmo tempo na direção fixa do eixo magnético do íma, de tal forma que (compare com a Seção 5)

$\alpha=M \cos (M, x), \beta=M \cos (M, y), \gamma=M \cos (M, z)$.

Para que - na ausência de outras forças - o íma encontrese em equilíbrio num campo homogêneo, tem de valer

$$
\mathcal{M}_{x}=\mathcal{M}_{y}=\mathcal{M}_{z}=0
$$

de onde segue imediatamente

$$
\alpha: \beta: \gamma=X: Y: Z
$$

isto é

$$
\cos (M, x): \cos (M, y): \cos (M, z)=\cos (\Re, x): \cos (\Re, y): \cos (\Re, z)
$$

O eixo magnético tem também de incidir na direção do campo magnético.

Se esta condição não é satisfeita, surge um momento de torção resultante

$$
\sqrt{(\beta Z-\gamma Y)^{2}+(\gamma X-\alpha Z)^{2}+(\alpha Y-\beta X)^{2}}=M \Re \operatorname{sen}(M, \Re)
$$

ao redor de um eixo cujo cosseno diretor comporta-se como

$$
\beta Z-\gamma Y: \gamma X-\alpha Z: \alpha Y-\beta X
$$

Este eixo é portanto perpendicular às direções de $M \mathrm{e}$ de $\Re$.

Como neste caso é nula a força translatória, vem de um teorema conhecido que o momento de torção é igual ao redor de todos os eixos paralelos.

A discussão seguinte da Seção 6 torna-se facilmente entendida, quando substitui-se o momento de torção por duas forças $\frac{M \Re}{r}$ direcionadas para $\Re$ e para a direção oposta, cujos pontos de atuação estão situados nas extremidades de uma linha de comprimento $r$ paralela ao eixo magnético.

\section{Sobre a Seção 7.}

2) O íma gira daqui em diante ao redor de um ponto $C$, o campo magnético homogêneo é o da terra, e também é levado em consideração o efeito do peso da massa do íma.

Transferimos a origem do nosso sistema de coordenadas para $C$, tomamos $x$ horizontal no meridiano magnético apontando em direção ao Norte, $y$ perpendicular a este apontando em direção ao Leste, $z$ vertical apontando para cima, e temos, quando pensamos na massa $m$ do íma concentrada em seu centro de gravidade $x_{1}, y_{1}, z_{1}$, e assumimos um momento de torção nulo ao redor dos eixos coordenados

$$
\begin{aligned}
& \beta Z-y_{1} m g=0 \\
& \gamma X-\alpha Z+x_{1} m g=0 \\
& -\beta X=0 .
\end{aligned}
$$

Aqui $g$ significa a aceleração da gravidade; a componente Y se anula para o sistema de coordenadas escolhido.

Da última equação segue-se que $\beta=0$, isto é, o eixo magnético tem de estar perpendicular a $y$, portanto situado no meridiano magnético. Levando em consideração que $\beta=0$ resulta da primeira equação que $y_{1}=0$, isto é, o centro de gravidade do íma tem de encontrar-se no plano meridiano magnético através de $C$.

\footnotetext{
${ }^{23}$ A designação não corresponde à de Gauss, que não é apropriada para a utilização de coordenadas ortogonais.
} 
Para interpretar finalmente a segunda equação, notamos que se $\Re$ representa a intensidade total [do campo magnético] e $i$ sua inclinação:

$$
X=\Re \cos i, Z=-\Re \operatorname{sen} i
$$

e

$$
\alpha=M \cos \vartheta, \gamma=-M \operatorname{sen} \vartheta
$$

onde $\vartheta$ é a inclinação do eixo magnético em relação à horizontal.

Seja além disto $S$ o centro de gravidade, $C S=s$, e $\sigma$ o ângulo entre $C S$ e o eixo $x$, assim a segunda equação transforma-se em

$$
-M \Re \operatorname{sen}(\vartheta-i)+m g s \cos \sigma=0,
$$

isto é, o momento de torção do magnetismo terrestre e do centro de gravidade ao redor do eixo $y$ têm de se anular.

A forma modificada que Gauss deu a esta condição, resulta assim:

O efeito da componente vertical do magnetismo terrestre é substituído por Gauss (comparar a Seção 6) por uma transferência do centro de gravidade na direção do eixo magnético, que na nossa designação é

$$
r^{\prime}=\frac{M \Re \operatorname{sen} i}{m g}
$$
forma:

Com a introdução de $r^{6}$ assume a segunda equação a

$$
-M X \operatorname{sen} \vartheta+m g\left[r^{\prime} \cos \vartheta+x_{1}\right]=0
$$

mas $r^{\prime} \cos \vartheta+x_{1}$ é a distância do centro de gravidade substituído até a vertical situada através de $C$ (o eixo $z)$, e $M X \operatorname{sen} \vartheta$ é a grandeza representada por Gauss por $M T \operatorname{sen} i$.

Deseja-se agora realizar as oscilações do íma ao redor da vertical $z$.
Girando-se o plano vertical situado através do eixo magnético para fora do meridiano magnético por um ângulo $u$, então

$$
\beta=M \cos \vartheta \operatorname{sen} u
$$

de onde, se $K$ significa o momento de inércia, a equação de movimento torna-se

$$
K \frac{d^{2} u}{d t^{2}}=-M X \cos \vartheta_{\operatorname{sen}} u
$$

Seja $t$ o período de oscilação reduzido a amplitudes infinitesimalmente pequenas, então como se sabe

$$
M X=\frac{\pi^{2} K}{t^{2} \cos \vartheta}
$$

ou na representação de Gauss:

$$
M T=\frac{\pi^{2} K}{t^{2} \cos i}
$$

Sobre a Seção 8.

3) Atualmente é habitual designar a grandeza $\frac{\Theta}{T M}=\frac{1}{n}$ por "relação de torção".

O fundamento das experiências para a determinação de $n$ é simples.

A influência da torção no período de oscilação resulta nas seguintes medidas. Tomando a diferença das equações para o equilíbrio e movimento

$$
\begin{aligned}
& 0=-T M \operatorname{sen} u^{\circ}+\Theta\left(v-u^{\circ}\right), \\
& K \frac{d^{2} u}{d t^{2}}=-T M \operatorname{sen} u+\Theta(v-u),
\end{aligned}
$$

segue-se (pois $u^{\circ}$ é constante):

$$
K \frac{d^{2}\left(u-u^{\circ}\right)}{d t^{2}}=-T M\left(\operatorname{sen} u-\operatorname{sen} u^{\circ}\right)-\Theta\left(u-u^{\circ}\right) .
$$

Temos

$$
\operatorname{sen} u-\operatorname{sen} u^{\circ}=\operatorname{sen}\left(u-u^{\circ}\right) \cos u^{\circ}-\operatorname{sen} u^{\circ}\left[1-\cos \left(u-u^{\circ}\right)\right]=\operatorname{sen}\left(u-u^{\circ}\right) \cos u^{\circ}\left[1-\operatorname{tg} u^{\circ} \operatorname{tg} \frac{u-u^{\circ}}{2}\right]
$$

Para demonstrações toleravelmente cuidadosas a experiência não diferencia $\cos u^{\circ}\left[1-\operatorname{tg} u^{\circ} \operatorname{tg} \frac{u-u^{\circ}}{2}\right]$ apreciavelmente de 1; substituindo além disto $\Theta\left(u-u^{\circ}\right)$ por $\Theta \operatorname{sen}\left(u-u^{\circ}\right)$ vem:

$$
K \frac{d^{2}\left(u-u^{\circ}\right)}{d t^{2}}=-(T M+\Theta) \operatorname{sen}\left(u-u^{\circ}\right)=-T M\left(\frac{n+1}{n}\right) \operatorname{sen}\left(u-u^{\circ}\right),
$$

de onde se deriva imediatamente, que através da torção o período de oscilação para amplitudes infinitamente pequenas diminui na relação de $1: \sqrt{\frac{n}{n+1}}$.

Sobre a Seção 10.
4) A maneira escolhida por Gauss de colocação do peso traz inconvenientes de fixação, pois mesmo pelas oscilações pode ocorrer um movimento giratório ao redor das pontas, pelo qual conforme as circunstâncias as oscilações podem 
ser aceleradas ou retardadas. Seria melhor uma suspensão em corte em vez de em ponta; atualmente utiliza-se pelo exemplo de W. Weber principalmente cilindros perfurados, que são presos em agulhas verticais em suportes magnéticos, de tal forma que um movimento relativo é excluído ${ }^{24}$.

Fechner apontou primeiro uma outra correção não secundária $^{25}$. A saber, o íma principal situa-se nas observações de oscilações com sua direção mais longa próxima do meridiano magnético, nas observações de desvio perpendicular ao mesmo. Na primeira situação sofre seu momento um aumento devido à força magnetizante da intensidade horizontal, o qual desaparece imediatamente se o íma é colocado perpendicularmente ao meridiano magnético. W. Weber ${ }^{26}$ indicou um procedimento para verificar esta redução e realizar os cálculos.

Como os coeficientes de temperatura do momento magnético até para bons ímas mostram diferenças não insignificantes $(0,001-0,0003$ para 1 grau Celsius $)$, para se atingir a precisão mais elevada deve-se determinar os coeficientes de temperatura do íma principal e derivar as variações da componente horizontal das oscilações de um segundo íma com coeficientes de temperatura igualmente conhecidos ou das indicações de um, variômetro especial para a intensidade horizontal“. Tal variômetro de intensidade foi construído pela primeira vez pelo próprio Gauss ${ }^{27}$; para o uso portátil há os instrumentos de F. Kohlrausch ${ }^{28}$.

Um método preciso para a determinação dos coeficientes de temperatura do momento magnético foi fornecido por W. Weber ${ }^{29}$.

Sobre as Seções 17 e 18.

5) Também para um iniciante não trarão dificuldades consideráveis os desenvolvimentos da Seção 16 para a teoria das observações de desvio; as sugestões seguintes podem facilitar a compreensão da Seção 17.

Por causa da equação

$$
m T \operatorname{sen} u^{\circ}+\Theta \operatorname{sen}\left(u^{\circ}-N\right)=0
$$

tem-se

$$
\begin{gathered}
m T \operatorname{sen} u+\Theta \operatorname{sen}(u-N)=m T\left(\operatorname{sen} u-\operatorname{sen} u^{\circ}\right)+\Theta\left[\operatorname{sen}(u-N)-\operatorname{sen}\left(u^{\circ}-N\right)\right] . \\
\operatorname{sen} u-\operatorname{sen} u^{\circ}=\operatorname{sen}\left(u-u^{\circ}\right) \cos u^{\circ}-\operatorname{sen} u^{\circ}\left[1-\cos \left(u-u^{\circ}\right)\right],
\end{gathered}
$$

ignora-se o segundo termo e transforma a outra diferença de senos correspondente, assim obtem-se

$$
\left[m T \cos u^{\circ}+\Theta \cos \left(u^{\circ}-N\right)\right] \operatorname{sen}\left(u-u^{\circ}\right)
$$

A forma da série para $\operatorname{tg}\left(u-u^{\circ}\right)$ resulta assim.

Em primeiro lugar nota-se que $f, f^{\star}, f^{\prime \prime} \ldots$ contêm nenhum termo livre de $\cos (\psi-u)$ e $\operatorname{sen}(\psi-u)$. Na equação

$$
(m T+\Theta) \operatorname{sen}\left(u-u^{\circ}\right)=f R^{-(n+1)}+f^{\prime} R^{-(n+2)}+\ldots
$$

introduz-se

$$
\begin{aligned}
& \operatorname{sen}(\psi-u)=\operatorname{sen}\left(\psi-u^{\circ}\right) \cos \left(u-u^{\circ}\right)-\cos \left(\psi-u^{\circ}\right) \operatorname{sen}\left(u-u^{\circ}\right) \\
& \cos (\psi-u)=\cos \left(\psi-u^{\circ}\right) \cos \left(u-u^{\circ}\right)+\operatorname{sen}\left(\psi-u^{\circ}\right) \operatorname{sen}\left(u-u^{\circ}\right)
\end{aligned}
$$

assim surgem no desenvolvimento de $f, f^{\star}, f^{\prime \prime}$... em primeiro lugar as mesmas funções de $u^{\circ}$ (em vez de $u$ ) multiplicadas numa potência de $\cos \left(u-u^{\circ}\right)$, após isto termos com $\operatorname{sen}\left(u-u^{\circ}\right)$ e assim por diante.

Como agora $\operatorname{sen}\left(u-u^{\circ}\right)$ é da ordem de grandeza de $R^{-(n+1)}$ e $\cos \left(u-u^{\circ}\right)$ só se diferencia de 1 com termos da ordem $R^{-(2 n+2)}$, então, se ainda para abreviar coloca-se

$$
\begin{aligned}
& f=m M \times\left\{\begin{array}{c}
{\left[n \cos (\psi-U) \operatorname{sen}\left(\psi-u^{\circ}\right)+\operatorname{sen}(\psi-U) \cos \left(\psi-u^{\circ}\right)\right] \cos \left(u-u^{\circ}\right)} \\
-\left[n \cos (\psi-U) \cos \left(\psi-u^{\circ}\right)-\operatorname{sen}(\psi-U) \operatorname{sen}\left(\psi-u^{\circ}\right)\right] \operatorname{sen}\left(u-u^{\circ}\right)
\end{array}\right\} \\
& =m M\left\{C \cos \left(u-u^{\circ}\right)-S \operatorname{sen}\left(u-u^{\circ}\right)\right\}
\end{aligned}
$$

teremos:

\footnotetext{
${ }^{24}$ Ver também Dorn, Wied. Ann. 17, p. 788, 1882. Kreichgauer, Wied. Ann. 25, p. 273, 1885.

${ }^{25}$ Fechner, Pogg. Ann. 55, p. 189, 1842.

${ }^{26}$ W. Weber, Werke (Obras), Vol. II, p. 336. (Abh. der Gött. Ges. d. Wiss. Vol. 6, 1855.) Comparar além disto Dorn, Wied. Ann. 17, p. 776, 1882; igualmente 35 , p. 270 e $275,1888$.

${ }^{27}$ Gauss, Resultate aus den Beobachtungen des magnetischen Vereins im Jahre 1837, p. 1.

${ }^{28}$ F. Kohlrausch, Wied. Ann. 19, p. 132, 1883.

${ }^{29}$ W. Weber, Resultate aus den Beobachtungen des magnetischen Verein im Jahre 1837, p. 38. (Werke, Vol. II, p. 58.)
} 


$$
\begin{aligned}
& (m T+\Theta) \operatorname{sen}\left(u-u^{\circ}\right)=m M\left\{C \cos \left(u-u^{\circ}\right)-S \operatorname{sen}\left(u-u^{\circ}\right)\right\} R^{-(n+1)} \\
& +f_{o}^{\prime} R^{-(n+2)}+f_{o}^{\prime \prime} R^{-(n+3)}+\ldots f_{o}^{(n+1)} R^{-(2 n+2)}+\Phi,
\end{aligned}
$$

onde $\Phi$ reune os termos seguintes, os quais não são constituídos tão facilmente e o índice $o$ significa a substituição de $u^{\circ}$ em vez de $u$.

Trabalha-se agora o termo com $S \operatorname{sen}\left(u-u^{\circ}\right)$ do lado esquerdo, dividido com

$$
\left\{(m T+\Theta)+m M S R^{-(n+1)}\right\} \cos \left(u-u^{\circ}\right)
$$

e desenvolve em potências de $R$.

Obtem-se então levando em consideração a observação acima feita sobre $\cos \left(u-u^{\circ}\right)$

$$
\begin{aligned}
& \operatorname{tg}\left(u-u^{\circ}\right)=\frac{m M C}{m T+\Theta} R^{-(n+1)}+\frac{f_{o}^{\prime}}{m T+\Theta} R^{-(n+2)}+\ldots \\
& \frac{f_{o}^{(n)}}{m T+\Theta} R^{-(2 n+1)}+\left\{\frac{f_{o}^{(n+1)}}{m T+\Theta}-\frac{m^{2} M^{2} S C}{(m T+\Theta)^{2}}\right\} R^{-(2 n+2)}+\Phi^{\prime}
\end{aligned}
$$

na qual $\Phi^{\prime}$ reune os termos seguintes.

Esta fórmula contem em primeiro lugar o resultado de Gauss para $t g\left(u-u^{\circ}\right)$ e leva facilmente ao desenvolvimento da Seção 18.

Como $\operatorname{arctg} \alpha=\alpha-\frac{1}{3} \alpha^{3}+\ldots$, assim diferencia-se da antecedente uma série derivada para $u-u^{\circ}$ em primeiro lugar em termos da ordem $-(3 n+3)$.

Mudando-se o ângulo $\psi$ de $\pi$, assim mudam $f^{6}, f^{\text {" }}$... seus sinais, enquanto que $S$ e $C$ mantêm os mesmos valores. Do valor médio de $\frac{1}{2}\left(u^{\prime}+u^{\prime \prime \prime}\right)$ e $\frac{1}{2}\left(u^{\prime \prime}+u^{\prime \prime \prime \prime}\right)$ caem fora portanto $f^{\prime}, f^{\prime \prime \prime}$...
Aumentando-se por outro lado $U$ em $\pi$, transformam-se $S$ e $C$ em seus opostos. No caso da natureza $(n=2)$ tiramse portanto na combinação $\frac{1}{4}\left(u^{\prime}-u^{\prime \prime}+u^{\prime \prime \prime}-u^{\prime \prime \prime \prime}\right)$ os termos com $R^{-4}$ e $R^{-6}$ e portanto também $\operatorname{tg} \frac{1}{4}\left(u^{\prime}-u^{\prime \prime}+u^{\prime \prime \prime}-\right.$ $\left.u^{\prime \prime \prime \prime}\right)$ que tem a forma especificada por Gauss ${ }^{30}$ :

$\operatorname{tg} \frac{1}{4}\left(u^{\prime}-u^{\prime \prime}+u^{\prime \prime \prime}-u^{\prime \prime \prime \prime}\right)=L R^{-3}+L^{\prime} R^{-5}+L^{\prime \prime} R^{-7}+\ldots$

Halle a. S., 22 de setembro de 1893.

E. Dorn

${ }^{30}$ Comparar também Riecke, Pogg. Ann. 149, p. 62, 1873, e Wied. Ann. 8, p. 299, 1879. 